\title{
Application of a two-way partitioned method for predicting the wave- induced loads of a flexible containership
}

\author{
P.A.Lakshmynarayanana ${ }^{1}$ and P.Temarel ${ }^{1}$ \\ ${ }^{1}$ Fluid Structure Interactions Group, University of Southampton, U.K
}

\begin{abstract}
The symmetric motions and wave-induced loads of a flexible S-175 containership are investigated using a two-way implicit coupling between RANS/CFD and Finite Element Method, STARCCM+ and Abaqus, respectively. The meshing strategy adopted for the two-way coupling (co-simulation) is presented and discussed. The numerical predictions of symmetric motions and acceleration and vertical bending moment RAOs are compared against experimental measurements and other available numerical predictions. The nonlinearities in the wave-induced bending moments, expressed as higher order harmonics of the wave encounter frequency, 2-node contribution and asymmetry in hogging and sagging loads are predicted with good overall accuracy. The influence of structural damping on the nonlinear resonant vibration is also demonstrated.
\end{abstract}

Keywords: Hydroelasticity; partitioned FSI; RANS/CFD; wave-induced loads; nonlinearity; springing

\section{Introduction}

An in-depth understanding of the wave actions on floating bodies is essential in accurately predicting their responses, and using these predictions in the design and strength assessment of ships and offshore structures. In recent years, there has been a rise in the size of commercial ships due to the increasing demands of the global sea trade. Consequently, it has resulted in relatively more flexible structures whose natural frequencies fall in the range of encounter frequencies commonly occurring in ocean wave spectra. This has given rise to a situation where the deformations of the structure can no longer be considered as negligible and the traditional rigid body approximations may result in inaccurate predictions of motion and wave loads on the structures. The deformations of the relatively more 'softer' structures can affect the flow around the body, the hydrodynamic loading and the structural responses; thus, requiring a fully coupled fluid-structure interaction, termed as Hydroelasticity. The hull girder flexibility can amplify the hull girder stresses and contribute to fatigue damage and extreme hull girder loading and calculated design bending moments neglecting such effects, say for a large container ship, can be largely underestimated (Andersen, 2014). 
The rule-based approach adopted by Classification Societies for the design and calculations of the strength of ship structure is based on empirical formulae derived from theory and experience. Hydroelastic effects, more often than not, are considered by specifying safety factors to account for the transient dynamic load effects on flexible hulls. Various numerical methods can be employed to investigate and quantify these effects, which will help us get better insights into the phenomena and aid in optimising these safety factors in the structural strength calculation in the rules and regulations.

Current experimental hydroelastic investigations focus on flexible backbone models (Jiao et al., 2019 and Jiao et al., 2019a), whereas numerical methods range from linear to partially nonlinear potential flow solvers (Hirdaris and Temarel, 2009). Numerical investigations of hydroealsticity of ships commenced with the 2-dimensional potential flow analysis of Bishop \& Price (1979) to improve the fluid-structure interaction taking into account the influence of flexible deformation of ship structures using a linear beam analysis and the corresponding interactions with the fluid forces using strip theory. They introduced the concept of generalised modes, allowing the inclusion of both rigid body and distortional degrees of freedom, to investigate the symmetric (Bishop et al., 1977), antisymmetric (Bishop et al., 1980) and unsymmetric (Bishop et al., 1986) responses of ships in waves. The linear 3-D hydroelasticity theory was first developed by Bishop et al. (1986) in frequency domain combining either 2-D or 3-D beam idealisations together with 3-D potential flow analysis using a pulsating source distribution over the mean wetted surface of the ship. A great deal of progress has been made since then in the development and application of frequency domain 3-D hydroelasticity analyses (e.g. Du et al., 1998; Malenica et al., 2003; Senjanovic et al., 2009 and Kim and Kim, 2014).

Calculations in frequency domain are faster and are useful in providing valuable insights in the early design stages of a vessel (ISSC., 2012). To represent weak nonlinearities under the linear hypothesis (small amplitude motions and waves), small perturbations can be applied in frequency domain (Zhao and Faltinsen, 1993), but this model is inaccurate when influenced by strong nonlinearities, say due to large amplitude motions. A ship in stochastic weather is subjected to various nonlinearities due to its motion and responses which requires investigations in time domain to model them accurately (ITTC, 2017). A benchmark study by comparing different nonlinear time domain computer codes for evaluating the vertical wave-induced bending moments was done by Watanabe \& Guedes Soares (1999). They compared various time domain codes from six different organisations that are based on weakly nonlinear methods. It was reported that the 
results obtained from the different codes are consistent in the linear range (low wave height region). However, they exhibit larger scatter in the larger wave height region where the elastic behaviour plays a significant role.

The rapid advances in computational efficiency resulted in the development of fully nonlinear methods to study the fluid-structure interaction of ships and other floating offshore installations. Mixed-Eulerian-Lagrangian (MEL) approach (Chapchap et al., 2011), CFD methods employing RANS (Weymouth et al., 2005) or even URANS models (Carrica et al., 2006), and particle methods (Baso et al., 2010 and Gao et al., 2012) are now being widely considered to investigate the nonlinear behaviour associated with responses of large floating structures. The dynamic response of a flexible structure on a free surface using the above nonlinear methods can be modelled by coupling it with a structural solver, for example a Finite Element solver. The numerical algorithms used to simulate FSI problems using coupled methods can be categorised as monolithic or partitioned, the latter being more commonly used since it can be implemented into existing codes easily. Algorithms that treat the governing fluid and structural equations as a unified system of equations, which is then solved concurrently are called monolithic FSI schemes (Michler et al., 2004). In partitioned methods, separate solvers for fluid and structures are employed such that single fields are exchanged at the interface sequentially and solved iteratively (Brummelen, 2011 and Tu et al., 2015).

The coupling between fluid and structural solvers can be broadly classified as one-way and two-way coupling. In the one-way coupling method, only the fluid pressures acting on the structure are transferred to the structural solver. The added mass effect due to the deformation of the structure is not accounted in this method (Benra et al., 2011). The structural deformations are fed back into the fluid solver causing mesh deformations in the two-way coupling. Takami et al. (2018) investigated the dynamic response of a large containership using one-way coupling and found that the vibratory components in the slamming pressures and the bending moments were not predicted accurately in this approach when compared to the experiments.

The two-way coupled analysis between CFD/RANS and FEA is being employed to study the springing and whipping behaviour of ships in waves. Paik et al. (2009) presented a coupled fluid-structure interaction method and compared the results of rigid, one-way and two-way coupling of S-175 containership with experiments. CFDShip-IOWA and ABAQUS were coupled for this investigation to study motions and structural loads during slamming event. The two-way coupled results showed good agreement with the 
measurements and captured well the ringing of the structure, which occurred mainly due to the bow flare slamming. Seng et al. (2012) presented a two-way coupling using OpenFOAM (CFD) and a non-uniform Timoshenko beam to evaluate the response of a 9600-TEU containership and compared with measurements and a weakly nonlinear code Shipstar. The structural responses were calculated using modal superposition. The peak values of VBM amidships predicted by CFD (two-way) and Shipstar were found to be $35 \%$ smaller than the measurements in one of the test cases.

Oberhagemann et al. (2012b) carried out time-domain simulations using nonlinear Navier-Stokes solver COMET and linear structural solver, based on finite element Timoshenko beam approach to study long-term extreme value analyses on marine structures. The paper concluded that the discretisation errors are a critical issue and using coarse grids, especially when flexibility is involved, lead to underestimated responses. Torsional and horizontal (antisymmetric) vibration in oblique seas for a 10,000 TEU containership using RANS/FE coupling using a modal decomposition method was later presented by Oberhagemann et al. (2012a). This was the first paper that investigated torsional vibration using a CFD based coupled solver. There has been a good deal of advancement in CFD and FEA coupled analysis to predict the hydroelastic behaviour of ships and offshore structures (Benhamou et al., 2018; El Moctar et al., 2017; Oberhagemann et al., 2015 and Sengupta et al., 2017). Nevertheless, there is a great deal of research and development that requires to be carried out through systematic validation and verification of various scenarios before a thorough confidence can be placed on these advanced hydroelastic methods. There are still differences in predictions when compared with experiments, especially when the nonlinearities are dominant (Lakshmynarayanana and Temarel, 2018, 2019). Additionally, the validations in case of nonlinear springing, whipping in beam seas, antisymmetric responses and irregular or extreme seas are scarce.

This paper presents the numerical computations of motions and wave induced loads on a flexible containership (S-175) advancing with a forward speed in regular head waves. A two-way coupling, referred to as co-simulation, between the CFD software Star-CCM+ and the FEA software Abaqus is applied. The main emphasis is on the prediction of wave loads and the influence of nonlinear effects for a range of wave frequencies. The nonlinearities are expressed as the higher order harmonics of the time series signals, high frequency 2-node flexible mode and the asymmetry in sagging and hogging loads. In addition, the influence of structural damping is also demonstrated. The co-simulation 
predictions are compared with a number of experimental measurements and other published numerical predictions, including 2-D hydroelasticity, showing its ability to capture the nonlinear effects even in relatively severe wave conditions. The generation of a suitably discretised FSI domain is essential for the accuracy of the co-simulation predictions, and the strategy adopted for this discretisation is discussed in this paper.

\section{Numerical Methods}

\subsection{Finite volume method}

The numerical method employed is a finite volume (FV) method in which the flow is assumed to be governed by RANS equations (Ferziger and Peric, 2003). The RANS equations reduce to the well-known Euler equations for the case of inviscid flow, used in this paper. First, the spatial fluid domain is discretized into a finite number of control volumes $(\mathrm{CVs})$. The integral form of conservation equations, with the initial and boundary conditions are then applied to the control volume centres and simplified into an algebraic system of equations solvable by the computer. The governing equations contain surface and volume integrals, as well as time and spatial derivatives. Apart from the conservation equations, the general transport equation for scalar quantities must also be satisfied in the control volume centres. In the numerical simulations of moving co-ordinates, e.g. when the boundaries are in motion in the flow (see section 2.4), an additional space conservation equation must also be satisfied. The space conservation equation ensures that the continuity and momentum equations are satisfied when the control volumes are moving arbitrarily (Peric et al., 2007). The governing equations are solved using a segregated iterative method, namely the SIMPLE (Semi-Implicit Method for PressureLinked Equations) algorithm (Patankar and Spalding, 1972). The Hybrid Gauss-Least Square gradient method is used to solve the transport equations. A detailed theoretical background can be found in Ferziger \& Peric (2003).

Free surface flows are implemented using the Volume of Fluid (VOF) tracking method (Hirt and Nichols, 1981). In order to account for the position of free surface in multiphase flows and allow for its arbitrary deformation, an additional transport equation is solved for the volume fraction $c$. In multiphase flows, the volume fraction $c$ is assigned a value of 0 when the cell consists entirely of air and when it is equal to 1 the cell is filled with only water. The air-water interface is represented by a volume fraction of 0.5. The HRIC (High Resolution Interface Capturing) discretization scheme is used for free surface flow along 
with the VOF tracking in to maintain a sharp interface (STAR-CCM+, 2012). The HRIC scheme is carried out by blending of upwind and downwind schemes and further corrected depending on the local Courant number (Muzaferija et al., 1998). A Cartesian mesh composed predominantly of hexahedral cells with trimmed cells next to the hull surface is used to discretise the fluid domain into control volumes, as detailed in section 4.1. The commercial CFD software Star-CCM+ is used in this research.

\section{$2.2 \quad$ Finite element method}

A displacement-based method where the basis of the finite element solution is the principle of virtual work or virtual displacements (Dassault Systèmes, 2013). A direct step-by-step integration is adopted in the present study where the governing equations are integrated over discretised time steps $\Delta t$. The temporal integration is performed using a dynamic-implicit scheme which uses the Hilber-Hughes-Taylor implicit operator which is an extension of the Newmark- $\beta$ scheme (Dassault Systèmes, 2013 and Clough \& Penzien, 1993). In the present method, the S-175 structure is modelled using 3-D beam elements (B31) and membrane elements (SFM3D4) are used to represent the wetted surface area of the ship that are connected to the beam nodes (see section 4.5.2).

\subsection{Coupling of CFD and FEM}

To simulate the hydroelastic effects of a flexible S-175 containership in waves, the fluid and structural solvers run in a coupled manner. A two-way coupling method between the solvers is used to perform this where the structural deformations, due to the applied fluid pressures, are fed back into the fluid solver to redefine the body and the fluid grid, as explained in the next section. A partitioned algorithm is used to execute the two-way coupling where separate solvers for fluid and structure are employed so that information is exchanged at the interface sequentially and solved iteratively. A two-way coupling can be further classified into explicit or implicit coupling. In some FSI problems, e.g. Static deformation of a flexible aerofoil in a 'steady-state' airflow, the interaction between the fluid and the structure will approach a steady-state solution where the structural velocities decrease to very small or even zero values. In these cases an explicit coupling, where the exchange of information takes places once per time step, can be used to calculate the 'steady-state' solution (Tallec \& Mouro, 2001 and Rugonyi \& Bathe, 2001). On the other hand, when the mutual dependency on time is high and a small change in one solver will have an immediate effect on the other an implicit coupling scheme is 
preferred (Causin et al., 2005). In the implicit coupling, used for the flexible containership in this paper, the information is exchanged between the software more than once every time step to simulate the change in hydrodynamic loading and structural velocities. The number of such exchanges per time step is critical for the stability and accuracy of the coupled simulations.

The coupling or co-simulation is carried out by exchanging pressure and nodal displacements, known as field data, between fluid and structural solver. Finite volume codes store the scalar quantities at each cell centre or the face centroid of the mesh and finite element codes store the solution at the vertices of the mesh. The CFD and FE meshes need not be conformal for mapping data (STAR-CCM+, 2012). In the present coupling method, face-to-face mapping in the coupling uses least square interpolations and node-to-face mapping uses shape function interpolation. In the shape function interpolation technique, the nodal displacements stored at the vertex of the FE mesh are interpolated to the face centroid of the fluid mesh using the shape functions. In the case of 3-D trimmed Cartesian CFD mesh hexahedral shape function is applied. The fluid pressures at the interface stored at the face centroid of the CVs are mapped on the face centres of the SFM3D4 membrane (surface) elements using least square interpolation.

\subsection{Grid adaptation techniques}

In the present investigations grid adaptation, as a consequence of the motion and deformation of the body at the free surface, is implemented using two different methods, namely 'morphing'/deforming mesh and 'overset' grids. The deformation of the body is carried out using 'morphing'. In the case of the co-simulation, the nodal displacements imported from Abaqus are used to redistribute the mesh vertices by generating an interpolation field throughout the fluid domain. A "space conservation law" is used to balance the volume of a $\mathrm{CV}$ as a function of time and the motion of the surface (Ferziger and Peric, 2003). Morphing could, however, create problems in the case of a body undergoing large motions in waves. The deformation of the entire grid could result in the free surface falling outside the refined region of the domain. Additionally, the quality of the deformed cells can become poor, resulting in numerical errors. To avoid this problem, an overset grid is used. An area around the body is defined as overset boundary in the overset region (see Figure 2). The overset boundaries are attached to the floating body and move with it freely, with the resultant motion in waves. The motion of the overset grid is relative to the background region that encompasses the fluid domain but is fixed 
in space. However, it should be noted that it is difficult to enforce global conservation when using overset grids, mainly in 3-D problems. For this reason the overset approach should be avoided for flows subject to large solution gradients or large regions of separated flows (Wang, 1995 and Tang et al., 2003). Generally, overset grids are highly efficient in the case of free surface flow, where the body undergoes large motions in waves.

A combination of overset mesh and mesh morphing is used in the case of the cosimulations to model the motion, including distortion where necessary, of the body. The nodal displacements from FEA, which includes both the rigid body motion and the distortions, cause a deformation of the body by generating an interpolation field. The overset boundaries then move in response to the interpolation field created by the mesh morpher that in turn helps to maintain good quality cells in the region.

\section{Numerical Simulations}

\subsection{Computational Domain and Grid Design}

The coordinate system of the computational domain is defined such that the longitudinal direction of the ship is aligned with the $\mathrm{x}$-axis with the stern located at $\mathrm{x}=0$ and the side wall extended along the $y$-axis. The mean free surface of wave lies at $z=0$. The domain was designed based on the minimum requirements prescribed by (ITTC, 2011). The extension of the computational domain in all directions is shown in Figure 1. Since the problem is symmetric with respect to the y-axis (only vertical motions and responses are calculated), the coupled analyses were carried out on one-half of the solution domain. A constant damping distance of $2.0 \mathrm{~L}_{\mathrm{pp}}$ is set for all incident wavelengths investigated.

A trimmed Cartesian grid is used for discretising the 3-D domain. The ensuing mesh was made up effectively of unstructured hexahedral cells with trimmed cells adjacent to the ship model. Furthermore, the outlet and the sidewall boundaries are extruded using user specified stretching parameters keeping into consideration that there is not any significant change in the grid sizes of the adjacent layers that could result in numerical issues. 


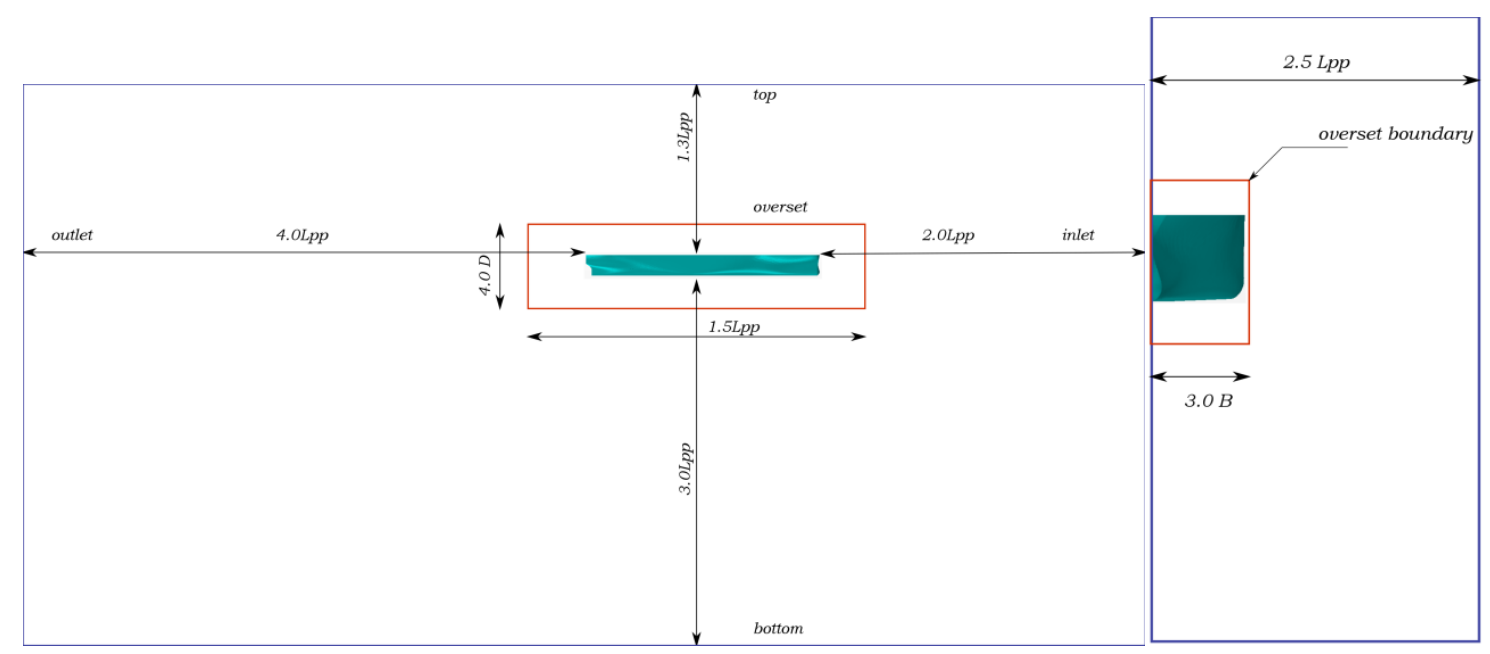

Figure 1: Overview of the computational domain and the distances towards the boundaries from the body.

The extent of the overset boundaries in the three-dimensions is also shown.

Taking into consideration the number of test cases that needs to be simulated for the validation study of S-175 in regular waves, it was decided to carry out computations on a single mesh for each wave height, suitable for the entire range of wave frequencies investigated. The meshing process followed on the experience attained from the cosimulation of the flexible barge (Lakshmynarayanana and Temarel, 2019). Please note that the ratios per wave length described below are the same for both the wave heights, although the cells sizes are different in the wave height region alone. Firstly, the grid size on the free surface is set for $\lambda / L=1.0$. Following the recommendations by ITTC (2011), 80 cells per wave length are used. The experience gathered from the coupled barge simulations (Lakshmynarayanana and Temarel, 2019) indicate that a minimum of 40 cells per wave length and 20 cells per wave height is sufficient to produce a stable wave with acceptable dissipation. Using the mesh created for $\mathrm{A} / \mathrm{L}=1.0$ for the other wavelengths, approximately 50 and 160 cells are contained per wave length for $\lambda \mathrm{L}=0.6$ and $\lambda \mathrm{L}=2.0$, respectively. Approximately 22 cells are contained per wave height in the free surface region for both wave heights investigated, namely $\mathrm{L} / 30$ and L/50, which is in line with standard recommendations (ITTC, 2011).

Thereafter, the refinements adjacent to the hull and in the wake region were calculated to adequately capture the severe free surface flows arising due to the green water effects and the wake field of the advancing ship. Kim \& Lee (2011), Tezdogan et al. (2015) and Piro (2013) suggest a around 150 grid cells per wave length near the hull surface in both upstream and downstream directions when severe motions inducing slamming and green water effects are present. Additionally, Piro (2013) also used refined grids at the bow 
region, approximately 29 grid points along the depth, to resolve the impact flow and water shipped on the deck.

In the co-simulations, for $N / L=1,160$ cells per wavelength (shown by the red box in Figure 2) are placed in the vicinity of the hull. Using this near hull refinement results in approximately 100 and 320 cells per wave length for $\lambda L=0.6$ and $\lambda / L=2.0$. In addition, the bow (shown by blue box in Figure 2) and stern contain 50 grid point refinement along the depth. Table 1 shows the global cell count of the background and the overset mesh. The refinements at the bow and in the wake region are shown in Figure 2 for $\mathrm{H}=\mathrm{L} / 50$.

It is evident from the snapshots in Figure 3 that the CFD simulations are able to capture the violent free surface flows that occurred at $\lambda / \mathrm{L}=0.9 \sim 1.5$, but no bow slamming events were detected. This was also observed in all the three experiments.

Table 1: Total cell count of the fluid grid for half model showing the distribution in the boundary and overset regions.

\begin{tabular}{cccc}
\hline Case Study & \multicolumn{2}{c}{ Cell count } & Total \\
\hline & Background & Overset & \\
S-175 $(\mathrm{H}=\mathrm{L} / 50)$ & $1,889,262$ & $1,667,020$ & $3,556,282$ \\
$\mathrm{~S}-175(\mathrm{H}=\mathrm{L} / 30)$ & $2,554,827$ & & $4,771,453$ \\
\end{tabular}

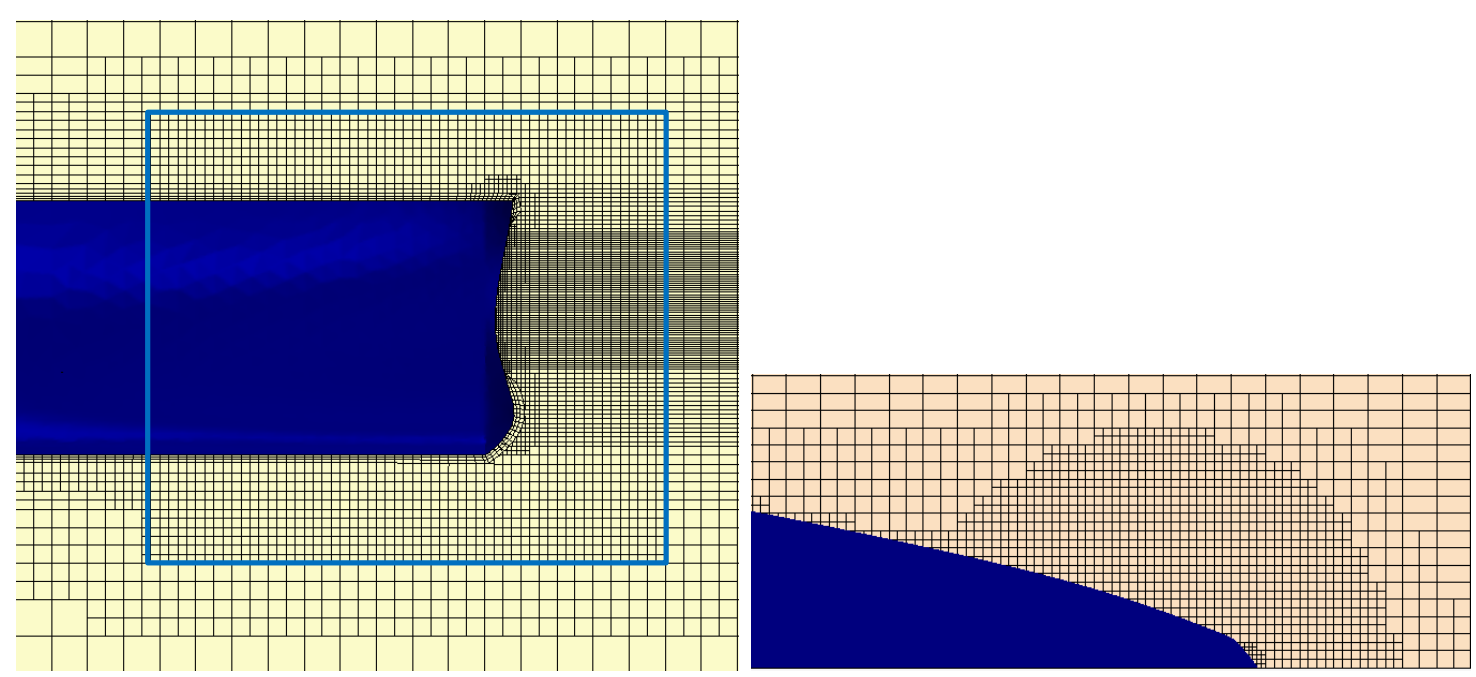




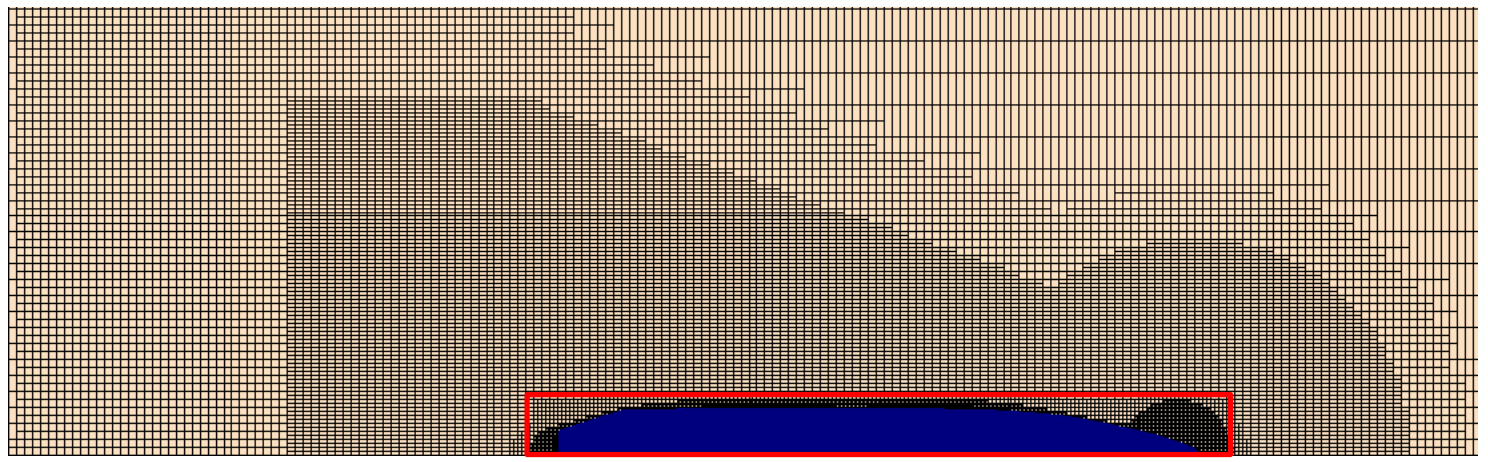

Figure 2: Grid refinement provided in the bow and wake region to capture the violent deck flows and the diffracted and radiated waves $(\mathrm{H}=\mathrm{L} / 50)$.
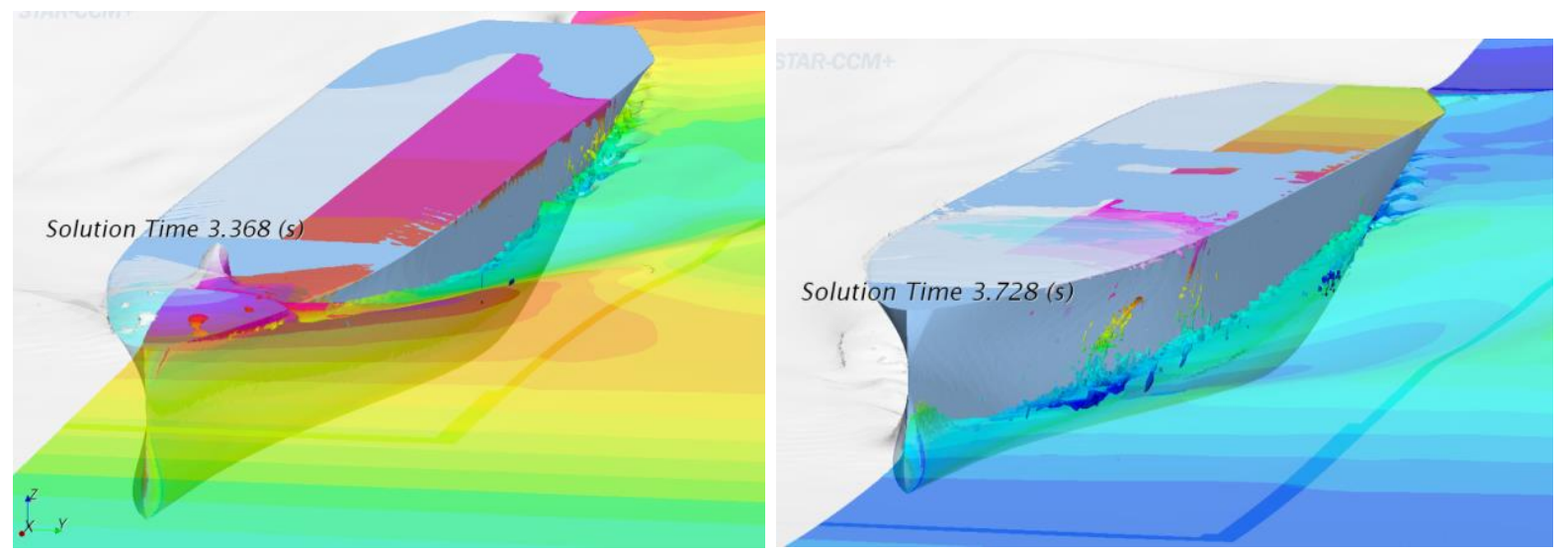

Figure 3: Contour plots of the CFD simulations for $\lambda / \mathrm{L}=1.3$ and $\mathrm{H}=\mathrm{L} / 50$ showing significant amount of water on the deck. For $\mathrm{H}=\mathrm{L} / 30$ the deck water shipped was found to be greater.

\subsection{Finite Element model of S-175}

The FE model of S-175 used in the co-simulation consists of beam elements which takes into account the flexibility of the ship in a global sense. The structural properties were calculated using scaling laws from the full scale mass and structural properties published by $\mathrm{Wu} \&$ Hermundstad (2002). The beam sections can only take into account linear material behaviour, although the section response can be linear or nonlinear. The structural model consists of 3-D quadratic Timoshenko beam elements, B31. A total of 100 beam elements are used. The material properties of the beam elements, corresponding to the flexible backbone of the model, are defined as that of Aluminium. The effective shear area was available (Wu \& Hermundstad, 2002) and was taken into account in the F E model. The shear stiffness has the units of force (Newton) and is equal to kAG, kA being the effective shear area and $G$ the shear modulus, taken as $2.6^{*} 10^{9} \mathrm{~N} / \mathrm{m}^{2}$. 
The hull surface is modelled using dummy surface elements (SFM3D4) and these are connected to the beam nodes using kinematic coupling constrains. The beam is shown in red colour in the FE model assembly shown in Figure 4. The hull is cut arbitrarily to illustrate the FE model details, with the beam positioned at a height corresponding to the VCG of the S-175.

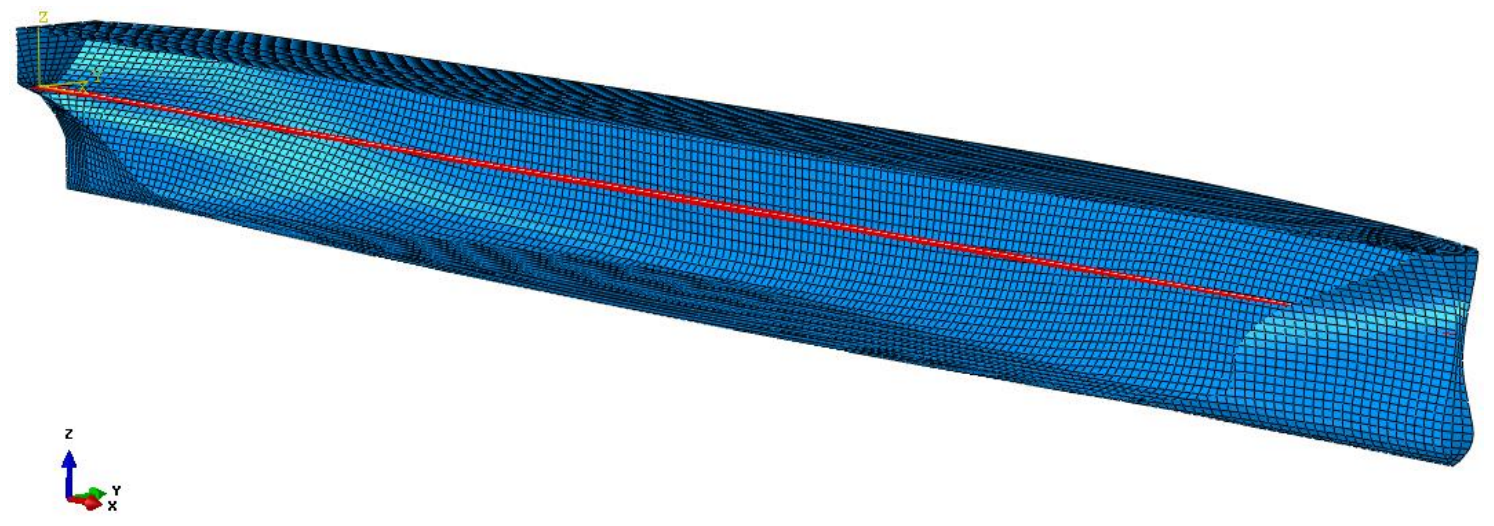

Figure 4: Perspective of S-175 FE model. The red coloured line represents the beam model.

The FE model is constrained for y-axis (no sway) translations and rotations about the $\mathrm{x}$ and z-axes (no roll and yaw) which is applied on the beam nodes. The forward velocity effects of the S-175 containership in the co-simulation is carried out by assigning an additional velocity of propagation, equal to the model velocity, to the regular wave. If the model is not restricted in the longitudinal direction in either the CFD or FE model it experiences a drift in direction of wave propagation due to longitudinal force. Furthermore, the time history of bending moment (BM_without_BC), shown in Figure 5, revealed a progressive decrease in its magnitude as the simulation proceeded, as well as a subsequent increase in the wave encounter period. The solution adopted to counteract this effect is to define an additional boundary condition in the FE model, restricting the unphysical drift in the longitudinal direction. An additional constraint of zero translation in the $\mathrm{x}$ direction to a beam node close to the LCG of the model is defined to restrict the longitudinal drift. The magnitude of bending moment with the boundary condition (BM_with_BC) is now steady and the period of the response is constant. 


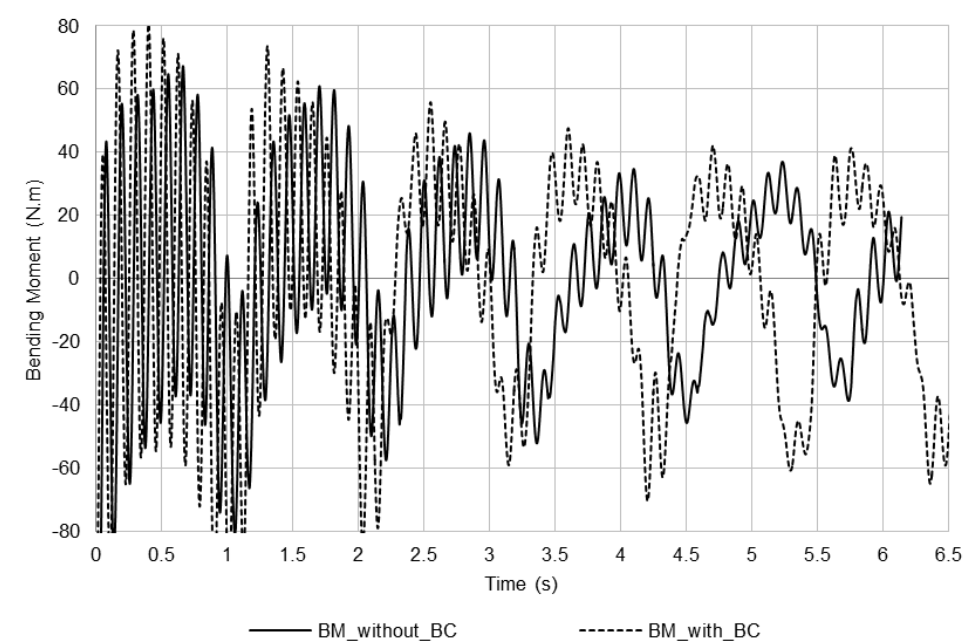

Figure 5: The time history of VBM amidships with and without the boundary condition to restrict the unphysical drift in the longitudinal axis. $\mathrm{H}=\mathrm{L} / 50$ and $\lambda / \mathrm{L}=1.0$.

\subsection{Boundary Conditions and Solver Settings}

The boundary conditions used in the CFD model of S-175 is given in Table 2. Boundary conditions of the fluid domain for both rigid and flexible simulations were selected so that they mimic the conditions of a towing tank. At the velocity inlet boundary the position of the free surface and velocity of the first-order wave are prescribed as field functions. The pressure at the outlet boundary is set to the hydrostatic pressure of the wave and additionally the position of free surface is specified. The top of the domain is set to velocity inlet as it prevents fluid from sticking to the walls, namely avoiding a velocity gradient happening between the fluid and the wall and in addition directing the flow parallel to the outlet boundary (Tezdogan et al., 2015). For the no-slip wall condition the fluid tangential velocity is set to zero. To save computational effort, a symmetry plane is used. The boundary condition on the symmetry plane ensures that the normal velocity and the normal gradients of all variables are zero mirroring the flow conditions on the other half of the domain.

The total number of inner iterations per time step is chosen to be twelve with four exchanges in one time step. Due to the violent free surface flows there was a restriction on the maximum time step, especially in the region of $\lambda / L=0.9 \sim 1.5$. In this region a constant time step of 0.0008 seconds was essential, which resolves the first natural period of the model into 145 time steps per period. Above this time step value, the simulations diverged due to interpolation error at the overset boundary and eventually crashed. When the body experiences violent flows and significant motions, finer time steps are required 
for the overlapping cells in the overset and the background region to be coupled at all times. With respect to the encounter wave period, for $\lambda \mathrm{L}=0.6 \sim 2.0$, the time step chosen varied between 1100 1600 time steps per wave period which is comparable to the available literature for similar computations (Peric et al. 2007, Paik et al. 2009 and Seng 2012). The simulations were run in parallel mode with single precision on the University of Southampton high power computing facility Iridis 4 . The test cases were run with 256 processors and it took between 7-10 hours to run 1 second of real time simulation. In general, the decrease in time step from 0.001 to 0.0008 seconds has a marked effect on the co-simulation time and the effect of increase in mesh size from $3.5 \mathrm{M}$ to $4.7 \mathrm{M}$ does not change the simulation time much for the same time step.

Table 2: The boundary condition used in the CFD model, including co-simulation

\begin{tabular}{lll}
\hline Region & Boundaries & Boundary Condition \\
\hline Domain & Inlet & velocity inlet \\
& Outlet & pressure outlet \\
& top & velocity inlet \\
& Bottom & no-slip wall \\
& side (y extent) & no-slip wall \\
& Symmetry & symmetry \\
Overset & S-175 & no-slip wall \\
& Boundaries & overset boundary \\
& Symmetry & symmetry \\
\hline
\end{tabular}

\section{S-175 Experimental Measurements}

The self-propelled $\left(\mathrm{F}_{\mathrm{n}}=0.275\right)$ model tests were conducted in the towing tank of the China Ship Scientific Research Centre (CSSRC), with tank dimensions of 474m (length) x 14m (width) x 7m (depth) (Chen et al., 2001). The elastic plate model of S-175 was made using ABS plate material ABS702. The main full-scale and model particulars for the S-175 are shown in Table 3. Due to the limitation in the thickness of the plate, the measured 2node frequency in water was $9.45 \mathrm{~Hz}$, rather than $8.57 \mathrm{~Hz}$ calculated by the law of similitude. Therefore, the structural similitude differed slightly as shown on Error! Reference source not found.3. In addition to the vertical bending moments, vertical accelerations at the FP, and heave and pitch motions were also measured. 
Table 3: Principal particulars of S-175 in full scale and model scale. * denotes the values calculated as per the law of similitude (Wu et al., 2003).

\begin{tabular}{lll}
\hline Particulars & Ship & Model \\
\hline Length between perpendiculars (L) & $175 \mathrm{~m}$ & $3.6 \mathrm{~m}$ \\
Draught (T) & $9.5 \mathrm{~m}$ & $0.195 \mathrm{~m}$ \\
Beam (B) & $25.4 \mathrm{~m}$ & $0.523 \mathrm{~m}$ \\
Depth (D) & $15.4 \mathrm{~m}$ & $0.317 \mathrm{~m}$ \\
EI (amidships) & $2.28 \times 10^{18} \mathrm{~kg} \cdot \mathrm{mm}^{2}$ & $* 8.4 \times 10^{9} \mathrm{~kg} \cdot \mathrm{mm}^{2}$ \\
& & $10.18 \mathrm{x} 10^{9} \mathrm{~kg}_{\mathrm{m}} \mathrm{mm}^{2}$ \\
2-node frequency (dry) & $1.6 \mathrm{~Hz}$ & $* 11.15 \mathrm{~Hz}$ \\
& & $12.27 \mathrm{~Hz}$ \\
2-node frequency (wet) & & $* 8.57 \mathrm{~Hz}$ \\
& & $9.45 \mathrm{~Hz}$ \\
\hline
\end{tabular}

The following additional experiments are also considered as a benchmark and vast majority of numerical validations utilise them. Watanabe et al. (1989) measured the effects of bow flare on deck wetness and the asymmetry in vertical bending moment on an elastic $\mathrm{S}-175\left(\mathrm{~F}_{\mathrm{n}}=0.25\right.$, head waves) model built using synthetic resin and foam urethane. The first and second harmonics of wave loads were reported in their paper. To study the influence of different wave heights on the nonlinear characteristic of the responses, Fonseca \& Guedes Soares (2004) tested a model comprising of three segments connected by springs, travelling at $\mathrm{F}_{\mathrm{n}}=0.25$ in regular head waves of varying frequencies. The amplitude and phase of the first, second and third harmonics of bending moments were obtained at amidships and $0.75 \mathrm{~L}$ from the aft perpendicular. Nonlinear effects were detected in both vertical motions and wave loads, although it was reported that they emerge stronger in the loads than in the motions.

Examining the results between the above three, experimental measurements unveiled some differences in the measurements, especially in the higher order harmonics. While Watanabe et al. (1989) and Chen et al. (2001) used elastic self-propelled S-175 model, Fonseca \& Guedes Soares (2004) used a towed segmented model. The type of the model and the forward speed effects could be contributing to the emerging differences. Although, the experiments by Chen et al. (2001) are used as a primary comparator in this study, the measurements of Fonseca \& Guedes Soares (2004b) and Watanabe et al. (1989) are also used to compare the numerical predictions. The expectation is that comparisons with 
different experiments will give a better awareness into the numerical uncertainties and aid in making recommendations on how they can be alleviated.

The primary differences between the three experiments and the co-simulations are listed in Error! Reference source not found.4. Error! Reference source not found.5 shows the regular head wave conditions that were used for the comparisons with the cosimulations. Even in the case of $H / \lambda=1 / 50$, where $H$ is the wave height and $\lambda$ is the wave length of the regular wave, a significant amount of green water and severe spray were observed in the model tests around the resonant frequency (ship-wave matching) region.

Table 4: Summary of certain key model and boundary conditions from the experiments and the cosimulation

\begin{tabular}{|c|c|c|c|c|c|}
\hline Cases & Model & $\begin{array}{l}\text { Fwd Speed } \\
\text { implementation }\end{array}$ & $\mathrm{H} / \mathrm{L}$ & Froude No: & EI(scaled) \\
\hline 1.Chen (2001) & $3.6 \mathrm{~m}$ & Self-Propelled & $1 / 50,1 / 30$ & 0.275 & $20 \%$ stiffer \\
\hline $\begin{array}{l}\text { 2.Watanabe } \\
\qquad(1989)\end{array}$ & $4.5 \mathrm{~m}$ & Self-Propelled & $1 / 30$ & 0.25 & $\begin{array}{l}\text { Similar to } \\
\text { scaled }\end{array}$ \\
\hline $\begin{array}{c}\text { 3.Fonseca } \\
\text { (2004) }\end{array}$ & $4.4 \mathrm{~m}$ & Towed & $1 / 50$ & 0.25 & $\begin{array}{l}\text { Similar to } \\
\text { scaled }\end{array}$ \\
\hline $\begin{array}{l}\text { 4. current co- } \\
\text { simulation }\end{array}$ & $3.6 \mathrm{~m}$ & $\begin{array}{l}\text { Fixed in position } \\
\text { and velocity }\end{array}$ & $1 / 50,1 / 30$ & 0.275 & $\begin{array}{l}\text { Similar to } \\
\text { scaled }\end{array}$ \\
\hline numerical & & input to incident & & & \\
\hline model & & wave & & & \\
\hline
\end{tabular}

Table 5: S-175 test cases simulated using the coupling technique

\begin{tabular}{ccc}
\hline Condition & Wave Height & $\mathrm{N} / \mathrm{L}$ \\
\hline 1 & $\mathrm{H}=\mathrm{L} / 50=72 \mathrm{~mm}$ & $0.6,0.7,0.8,0.9,1.0,1.1,1.2,1.3,1.5,2.0$ \\
2 & $\mathrm{H}=\mathrm{L} / 30=120 \mathrm{~mm}$ & $1.1,1.2,1.3$ \\
\hline
\end{tabular}

The vertical bending moments were calculated from the strain measurements (Chen et al., 2001). The location of measurement points are given inError! Reference source not found. and illustrated in Error! Reference source not found.6. Please note that in 
the experiments the bending moments were recorded on the starboard side-deck plate of the flexible model at the longitudinal locations shown in Error! Reference source not found.6. However, due to the application of beam model to carry out the present simulations the responses were calculated on the beam nodes corresponding to the longitudinal locations, albeit at the centreline of the vessel as shown in Error! Reference source not found.6. Watanabe et al. (1989) measured the bending moments at three locations, namely, L/4 (from stern), amidships and 3/4 L and Fonseca \& Guedes Soares (2004) only recorded at 3/4L (from stern) and amidships.

Table 6: Longitudinal locations where the motions and responses are calculated. $\mathrm{H}=\mathrm{L} / 30$ only amidships data available (Chen et al., 2001).

\begin{tabular}{ccc}
\hline Location & Station & Longitude \\
\hline 1 & Station 5 & $0.95 \mathrm{~m}$ from AP \\
2 & Station 7.5 & $1.35 \mathrm{~m}$ from AP \\
3 & Station 10 (amidships) & $1.85 \mathrm{~m}$ from AP \\
4 & Station 12.5 & $2.25 \mathrm{~m}$ from AP \\
5 & Station 15 & $2.65 \mathrm{~m}$ from AP \\
\hline
\end{tabular}

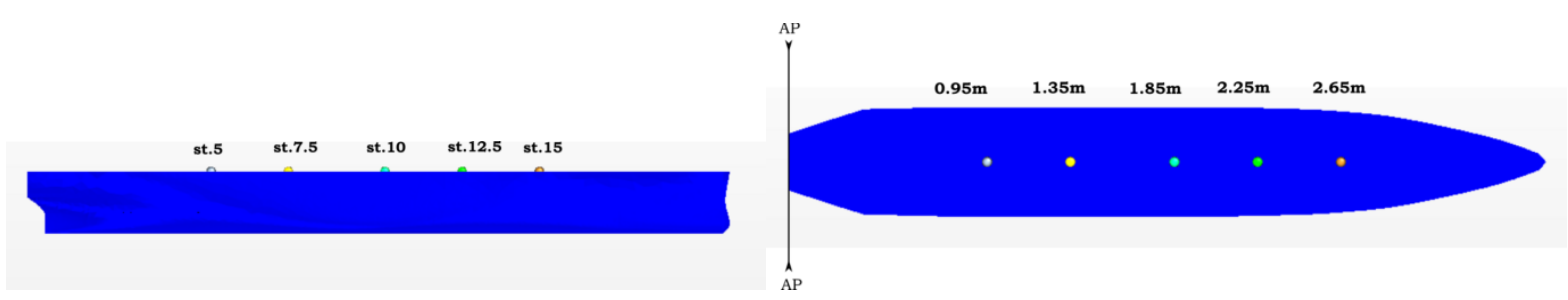

Figure 6: Pictorial representation depicting the side and top view of point probes placed on the model as per the measurements points in Chen et al. (2001)

To investigate the effect of higher order harmonics and springing components in the waveinduced loads, the time series signal of the vertical bending moment must be separated into the corresponding frequency components. The time series signal was decomposed into its sinusoidal frequency components using a Fourier transform. The transformed signals were then identified as first, second, third harmonics of the wave encounter frequency, as well as the springing component near the 2-node wet resonant frequency. Moreover, the amplitude of the corresponding frequency components was non-dimensionalised with 
respect to the wave heights. The non-dimensional amplitudes of heave, pitch, vertical accelerations and bending moment are given as follows:

$$
C_{z}=\frac{Z}{a_{w}}, C_{\theta}=\frac{\theta}{k a_{w}}, C_{A}=\frac{L \ddot{Z}}{g a_{w}}, C_{M}=\frac{M^{(i)}}{D}
$$

where $L$ denotes the length of the model; $g$, acceleration due to gravity; $k$, wave number; $Z$, heave amplitude; $\theta$, pitch amplitude, $\ddot{Z}$, vertical acceleration amplitude; $a_{w}=\mathrm{H} / 2$, wave amplitude. $M^{(i)}$ denotes the frequency component of bending moment as defined by the index $i$ and denominator $D$ is the parameter for non-dimensionalisation of the corresponding wave-load component, defines as follows:

$D=\rho g L^{2} B H$ for $M^{(i)}=M^{(1)}$ (double amplitude of first harmonic bending moment) $D=\rho g L^{2} B a_{w}$ for $M^{(i)}=M^{(2,3,2-n o d e)}$ (amplitude of $2^{\text {nd }}, 3^{\text {rd }}$ and 2-node bending moment. $M^{(s a g, h o g)}$ is also non-dimensionalised using the latter expression for D.

\section{Results and Discussion}

Numerical predictions of heave and pitch motions, vertical accelerations at the bow and vertical bending moments at amidships for the S-175 (model scale) at a Froude number of 0.275 for test conditions (seeError! Reference source not found. Error! Reference source not found.) are compared with available experimental measurements. Chen (2001), Watanabe (1989) and Fonseca (2004), respectively denote the references to the measurement by Chen et al (2001), Watanabe et al (1989) and Fonseca \& Guedes Soares (2004), in the figures.

The 2-D hydroelasticity method by Bishop et al. (1977) is used as a comparator for the applications. In this method, the structure is represented as a Timoshenko beam. 2-D strip theory is used to calculate the hydrodynamic actions on the body, using Lewis sections. Frequency dependent added mass and damping coefficients are evaluated. The resultant unified equations of motion in regular waves provide the requisite principal coordinates for a range of wave frequencies. Modal summation is employed to evaluate the vertical displacement and vertical bending moment (VBM) at a specified location along the S-175 containership. Rigid body displacements can be evaluated by excluding distortions. 
The numerical predictions obtained using 2-D hydroelasticity, rigid body CFD analysis (STARCCM+ only) and the co-simulation are denoted in the figures by 2-D Linear, CFD_rigid and CFD/FEA, respectively. When different wave heights are used, these are denoted by $\mathrm{L} / 30$ and $\mathrm{L} / 50$.

For the present numerical validations, Chen et al. (2001) is treated as the primary comparator. Nevertheless, the results from other experiments (given in Error! Reference source not found.4) are also used to discuss the validity of numerical predictions because of the differences in the model and operational conditions. It was not possible to exactly replicate the experimental conditions, for example, the numerical model is closer to a towed model than a self-propelled model. In spite of the differences, it is worthwhile to compare the results in general terms.

\subsection{Modal Analysis}

The first four dry natural frequencies of the model were evaluated using Block Laconzs eigen value extraction method. Table 7 presents the (dry) natural frequency of the FE model compared with calculations performed by 2-D finite difference method (Bishop et al., 1977), for the first two symmetric modes. There is good agreement between the FE models and the 2-D finite difference results.

Table 7: Dry natural symmetric frequencies $(\mathrm{Hz})$

of the S-175 model- in brackets ( $\mathrm{rad} / \mathrm{s})$.

\begin{tabular}{lll}
\hline Mode & Abaqus & Finite difference \\
\hline 2-node & $11.12(69.92)$ & $10.90(68.493)$ \\
3-node & $25.22(158.49)$ & $24.31(152.76)$ \\
& & \\
\hline
\end{tabular}

\subsection{Heave, Pitch and Vertical Acceleration in waves}

In the numerical analysis and in the experiment, the incoming wave is monitored at one ship length $(3.6 \mathrm{~m})$ in front of the model. When the ship motion is assumed to be linear, the motion and responses are commonly represented as transfer functions per wave amplitude known as Response Amplitude Operators (RAO). Average wave amplitude over the last stable 10 wave periods was used to calculate the RAOs of motions and loads. The incoming wave was stable as shown in Table 8 . The difference of approx. $5 \%$ and more 
is observed for the short wave lengths starting from $\lambda / L=0.8$ and lesser. The percentage differences also shows an increase with increase in wave steepness $(\mathrm{H} / \mathrm{L})$. First order regular wave model was implemented for the CFD simulations and the recommended wave steepness for this model is 1/100 and lesser (STARCCM+, 2012). For wave steepness, greater than $1 / 100$ it is advised to $5^{\text {th }}$-order Stokes wave. Apart from the mesh discretisation reported in this paper, a $5^{\text {th }}$ order stokes wave can be implemented to improve the differences in the wave heights in CFD simulations.

Table 8: Regular wave height data from the CFD simulations

\begin{tabular}{|c|c|c|c|c|c|}
\hline$\lambda / \mathrm{L}$ & $\lambda$ & $\mathrm{H}(\mathrm{CFD})$ & H (Input) & $\%$ difference & $\mathrm{H} / \mathrm{L}$ \\
\hline 0.6 & 2.16 & 0.067316 & 0.072 & -6.51 & $1 / 30$ \\
\hline 0.7 & 2.52 & 0.067836 & 0.072 & -5.78 & $1 / 35$ \\
\hline 0.8 & 2.88 & 0.06866 & 0.072 & -4.64 & $1 / 40$ \\
\hline 0.9 & 3.24 & 0.069446 & 0.072 & -3.55 & $1 / 45$ \\
\hline 1 & 3.6 & 0.069893 & 0.072 & -2.93 & $1 / 50$ \\
\hline 1.1 & 3.96 & 0.071 & 0.072 & -1.39 & $1 / 50$ \\
\hline 1.2 & 4.32 & 0.07 & 0.072 & -2.78 & $1 / 60$ \\
\hline 1.3 & 4.68 & 0.07059 & 0.072 & -1.96 & $1 / 65$ \\
\hline 1.5 & 5.4 & 0.071227 & 0.072 & -1.07 & $1 / 75$ \\
\hline 2 & 7.2 & 0.072177 & 0.072 & 0.25 & $1 / 100$ \\
\hline
\end{tabular}

The responses in this section are plotted against the non-dimensionlised wave frequency $\omega \sqrt{ }(\mathrm{L} / \mathrm{g})$, where $\omega$ is the incident wave frequency. The heave response as a function of the non-dimensionlised wave frequency is shown in Figure 7. In the numerical simulations, the total displacement of a point probe on the deck of the ship at LCG is used to record the time histories and the average amplitude over 10 complete cycles is used to calculate the RAO. 
The ship-wave matching resonance for the CFD predictions, as well as those from 2-D hydroelasticity, for $\mathrm{H}=\mathrm{L} / 50$ occurs in the vicinity of $\omega \sqrt{ }(\mathrm{L} / \mathrm{g}) \sim 2.2(\mathrm{~N} / \mathrm{L} \sim 1.1)$. For $\mathrm{H}=\mathrm{L} / 30$, this resonance occurs at a slightly higher value $(\omega \sqrt{ }(\mathrm{L} / \mathrm{g}) \sim 2.3)$. The position of this resonance is also confirmed by the measured results shown in Figure 7. The linear predictions largely over-estimate the heave RAO in the non-dimensionalised frequency of $1.7 \sim 2.5$ by about $40 \%$ when compared to the experiments. The co-simulation, for $\mathrm{H}=\mathrm{L} / 50$, produce slightly better results in this frequency range, but they are still larger than the measurements by $15-25 \%$. This difference can be noted in the frequency range of 2.0 2.6, where the bow of the model was immersed in the simulations shipping large amount of water on deck (Figure 3). The rigid body computations at $\mathrm{H}=\mathrm{L} / 50$ in the frequency range of 2.0 2.4 are slightly smaller than the co-simulations; hence the agreement is also closer to the experiments. The heave response predicted for the larger wave height, $\mathrm{H}=\mathrm{L} / 30$, shows better agreement when compared to measurements.

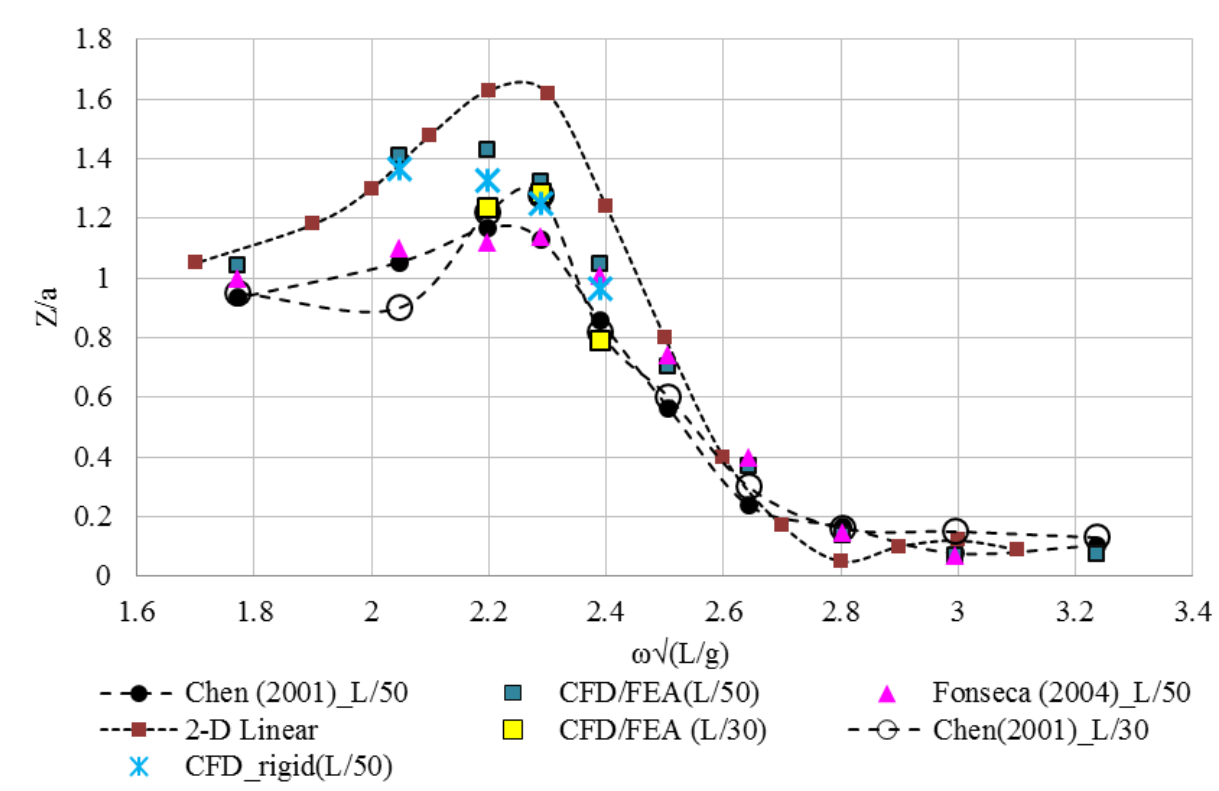

Figure 7: Non-dimensional heave amplitudes predicted from the coupled simulations compared with 2-D linear and experimental measurements.

Chen et al. (2001) indicates that a possible reason for the differences between measurements and 2-D linear predictions is due to the omission of viscous and nonlinear effects in the numerical model. Iijima et al. (2008) also found that the heave was overestimated by about 30\% in a similar frequency range using a 3-D linear potential flow code. Fonseca \& Guedes Soares (2005) introduced viscous effects to a nonlinear time domain code and reported that the heave amplitudes improved when compared to experiments. Following the above recommendations, two cases were simulated using a k- 
$\omega$ SST turbulence model. The heave response after including viscosity is shown in Table 9 and is now slightly lower than the inviscid case; nevertheless, the difference, at resonance, is still $15 \%$ at this frequency when compared to experiments.

Table 9: Heave calculated for two frequencies with and without viscosity compared with experimental measurements and 2-D linear.

\begin{tabular}{lllllll}
\hline$\lambda / \mathrm{L}$ & $\omega \sqrt{ }(\mathrm{L} / \mathrm{g})$ & CFD (inviscid) & CFD (Viscous) & Chen (2001) & Fonseca (2004) & 2-D Linear \\
\hline 1.3 & 2.19 & $1.428(22 \%)$ & $1.35(15 \%)$ & 1.17 & 1.1 & 1.4 \\
1.5 & 2.04 & $1.412(34 \%)$ & $1.3(24 \%)$ & 1.05 & 1.12 & 1.63 \\
\hline
\end{tabular}

The numerical predictions of the pitch RAO, shown in Figure 8, show good agreement with the experiments except in the non-dimensional frequency range of 2.0 2.2 where the pitch is over predicted. The magnitude of pitch angle is very small for this model in the range of $0.6 \sim 4.0$ degrees. The predictions in this region $(\omega \sqrt{ }(\mathrm{L} / \mathrm{g}) 2.0 \sim 2.2)$ are closer to the measurements conducted by Fonseca \& Guedes Soares (2004b). O’Dea et al. (1992) noted that the pitch motion for varying wave steepness was virtually linear. The CFD/FEA pitch RAO decreases by about $15 \%$ with increases in wave height. The measurements by Chen et al. (2001) exhibit a sharp decrease in the non-dimensionalised frequency region 2.0 2.2; not noted by other experimentalists, for either $\mathrm{H}=\mathrm{L} / 50$ or $\mathrm{H}=\mathrm{L} / 30$. Chen et al. (2001) do not offer a specific reasoning about this odd behaviour. The effect of distortion on pitch is very small when comparing the coupled (CFD/FEA) and rigid body (CFD_rigid) simulations, whereas the differences were larger for the heave RAO. The 2-D linear hydroelastic pitch RAO predictions agree better with the experiments and the cosimulations than the heave RAOs. 


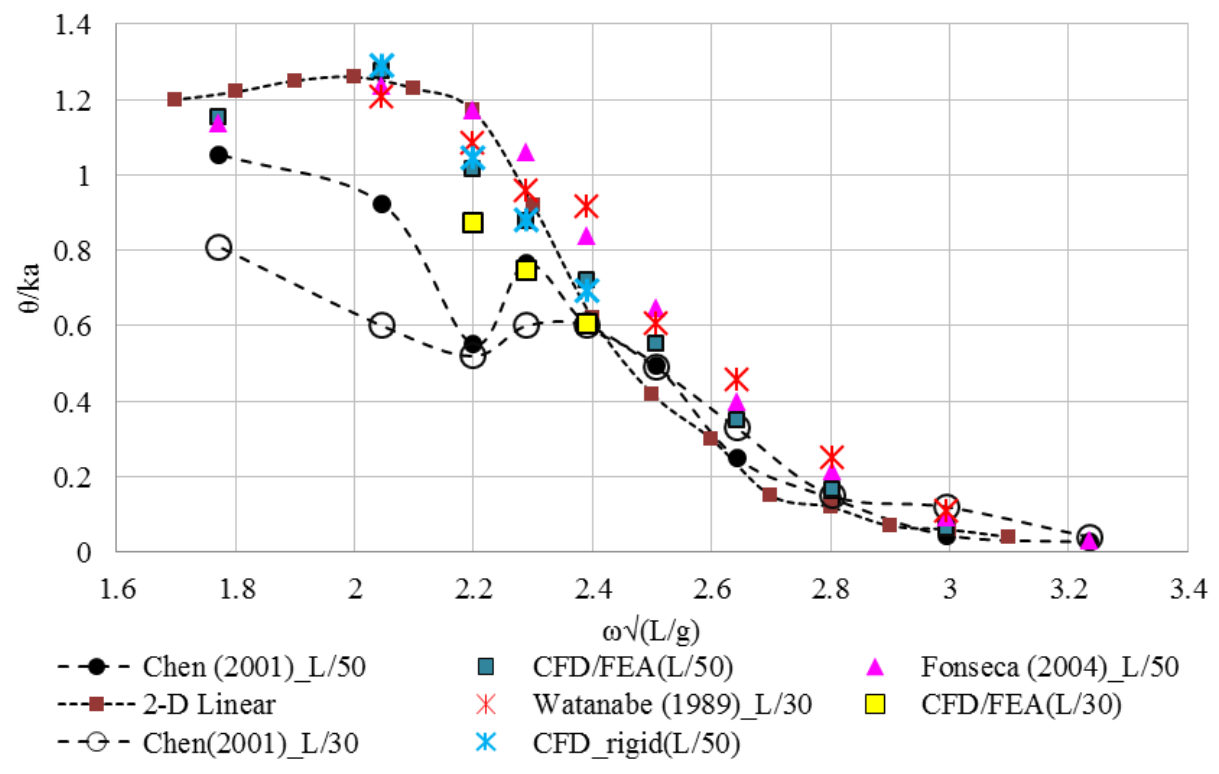

Figure 8: Non-dimensional pitch amplitudes predicted from coupled simulations with 2-D linear and experimental measurements.

The bow vertical accelerations (Figure 9) predicted by the 2-D linear theory are greater than the measurements, as well the CFD/FEA predictions, and the maximum difference of $38 \%$ is observed at the resonant non-dimensional frequency 2.3. The high-frequency component was filtered out of the time series signal to keep the comparison with the measurements consistent. The co-simulation results in Figure 9 shows remarkably good agreement with the measurements in the frequency range, with a maximum difference below 10\%. This indicates that the bow vertical acceleration which is sensitive to the nonlinearities arising in the cases is well captured in the simulations.

If we consider a simple sinusoidal equation of motion, say displacement $X=A \sin (\omega t)$ where $\mathrm{A}$ is the amplitude of motion, $\omega$ is the frequency and $\mathrm{t}$ is the time, the second time derivative of this motion $\ddot{X}$ will represent the acceleration. Therefore, we can say that the bow acceleration is a more sensitive indication of the higher order harmonics as the first, second and third harmonics will be proportional to $\omega^{2}, 4 \omega^{2}$ and $9 \omega^{2}$, respectively. The time histories of vertical bow accelerations clearly displayed nonlinear influences. The magnitude of the second harmonic component is in the range of about $5-12 \%$ of the first harmonic. The third harmonic component is much smaller and is less than $2 \%$ of the first harmonic. The higher order harmonics did not appear in the heave and pitch motions recorded in the co-simulations. 


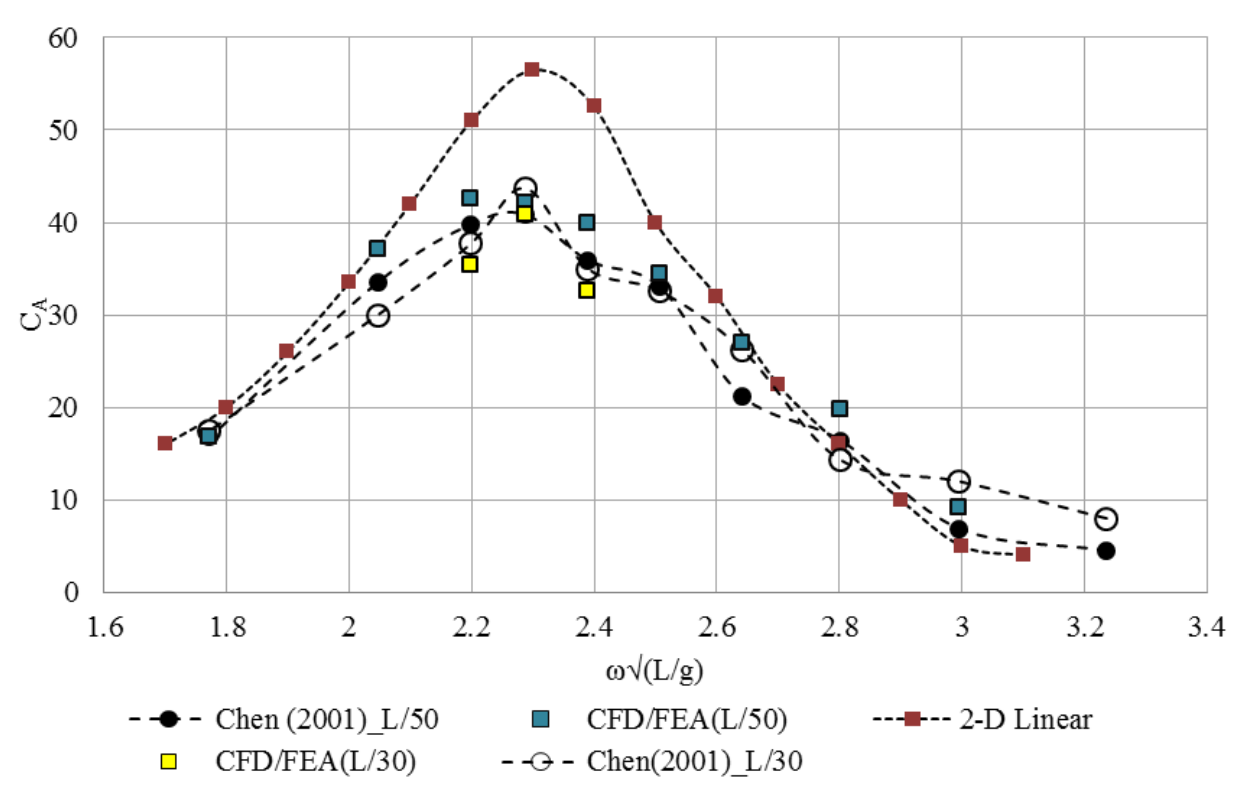

Figure 9: Non-dimensional vertical acceleration predicted from coupled simulations compared with 2-D linear and experimental measurements.

\subsection{Vertical Bending Moment in waves}

The first harmonic of wave bending moment amidships estimated using the co-simulation method is compared with 2-D linear, experimental measurements and with the nonlinear strip theory results from Wu \& Hermundstad (2002). Before proceeding to the forward velocity problem, the co-simulation was investigated for zero speed condition at two wave frequencies corresponding to a ratio of $\mathrm{X} / \mathrm{L}=1.3$ and 2.0, and compared with zero speed 2D linear predictions. This exercise is to check the differences between the two numerical methods when the steady forward speed effects are eliminated. The non-dimensional values of the first harmonic of bending moment amidships shown in Table 1010 are in close agreement at these two frequencies.

Table 10: VBM amidships for two wave conditions $(\mathrm{H} / \mathrm{L}=1 / 50)$ in zero speed condition.

\begin{tabular}{llll}
\hline$\lambda / \mathrm{L}$ & 2-D Linear & CFD/FEA & Difference (\%) \\
\hline 2.0 & 0.006145 & 0.0064752 & $5.4 \%$ \\
1.3 & 0.0119477 & 0.0112794 & $5.5 \%$ \\
\hline
\end{tabular}

Comparing the predictions with forward speed in Figure 10, the agreement between the two methods (i.e. 2-D linear and CFD/FEA) is seemingly good, but in the range of $\mathrm{N} / \mathrm{L}$ 
$=1.0 \sim 2.0$ where the 2-D linear, as well as nonlinear, predictions are larger. The difference between the non-dimensionalised bending moments approaches a maximum of about 18$20 \%$ in the region of non-dimensional frequency $1.5 \sim 2.0$. The bending moments predicted by the co-simulation in this region is under-predicted when compared to 2-D linear and even the experiments. In relatively shorter wave length, i.e. $\lambda / L=0.6 \sim 0.9$, the agreement between the co-simulation and the other two numerical methods is excellent, but not so much with the experiments.

The inlet boundary is placed at a distance of $2 \mathrm{~L}$ from the model which means for $\lambda / \mathrm{L}=2.0$ there is only one wavelength in front of the body. To assess the effect of the distance of the inlet from the body is increased to 4.0L. Additionally, to ascertain that the problem is not related to grid refinement, the initial mesh was globally refined by a factor of 1.4. The results shown in Table 111 reveal relatively small changes (about 1-2\% for first harmonic VBM) when compared to the original mesh. A detailed grid refinement study is not carried out in the coupled simulations of S-175 due to the computational time required to run very fine meshes. All the results presented are on the original grid; nonetheless, Table 111 suggests that error in responses calculated is within acceptable limits.

Table 11: Comparison between various grid configurations used to estimate the responses for $\lambda / \mathrm{L}=2.0$

\begin{tabular}{ccccccc}
\hline Grid & $1^{\text {st }}$ harmonic & $2^{\text {nd }}$ harmonic & $3^{\text {rd } h a r m o n i c}$ & 2-node & Heave & Cell count \\
\hline Original mesh & 0.005567 & 0.0006266 & 0.0002924 & 0.0005940 & 1.042 & 3.75 million \\
Extended inlet & 0.00555 & 0.0005122 & 0.0003440 & 0.0006915 & 1.059 & 4.2 million \\
Refined mesh & 0.005686 & 0.000657033 & 0.0003689 & 0.000589645 & 1.0455 \\
\hline
\end{tabular}

For $\mathrm{H}=\mathrm{L} / 50$ the bending moments comparisons between the present method and the experiment amidships produce small differences in the resonant (ship-wave matching) region; however, there is an over-prediction in the shorter waves by a maximum of about $35 \%$ and under prediction by the same amount in the longer waves. The correspondence between the co-simulation and the three experiments is good in the region of $\lambda / \mathrm{L}=1.0 \sim 1.3$. Some differences can also be noted between the different experiments but these are under $15 \%$. Increase in wave height causes an increase in the amidship bending moment by $10 \%$ in the coupled simulations. A definite peak is noted in Chen et al. (2001) at $\lambda / \mathrm{L}=1.2$ and the measurement is $15 \%$ greater than the simulations and the other experiments. 


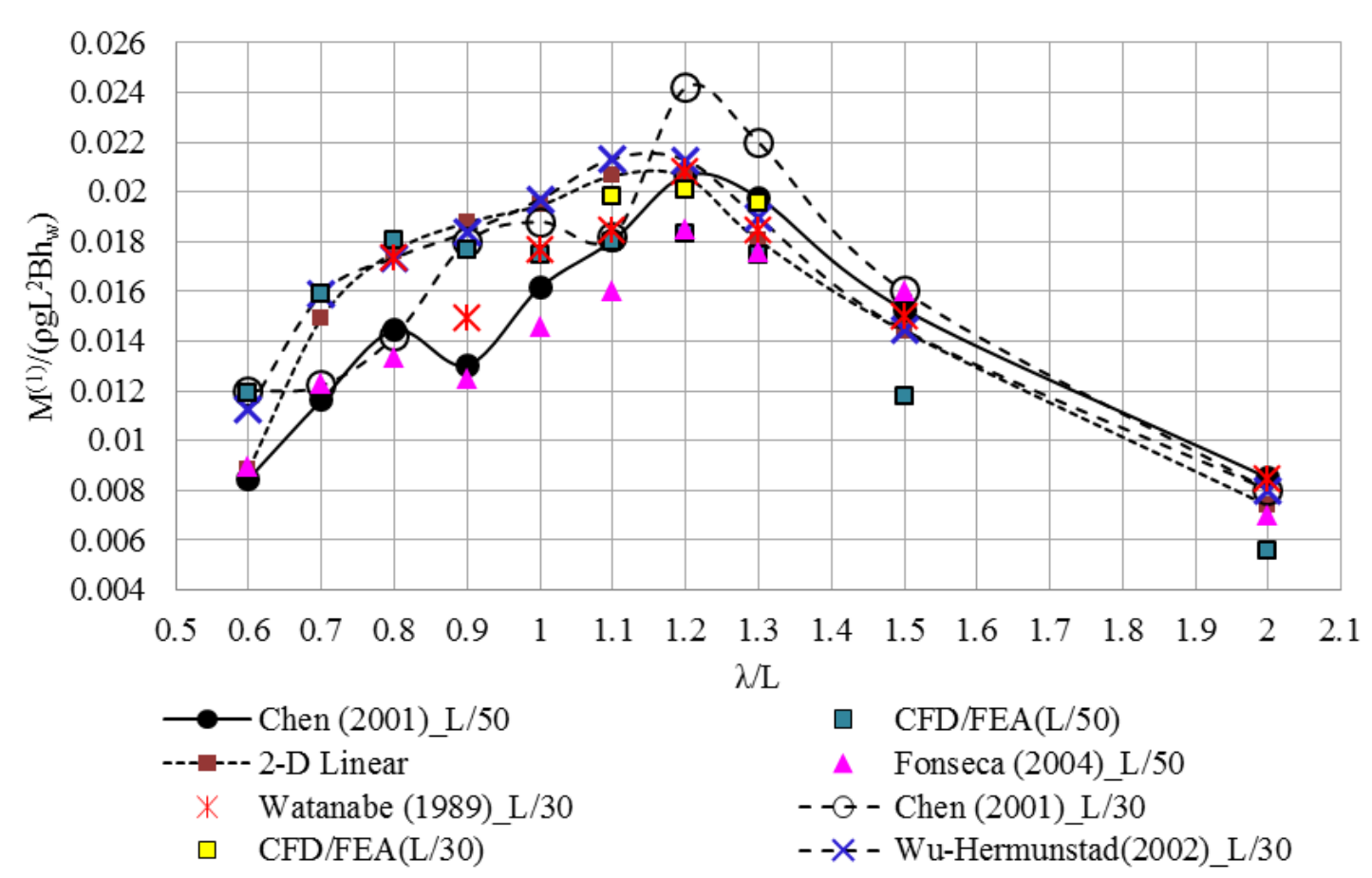

Figure 10: Non-dimensional amplitude of first harmonic VBM amidships calculated using co-simulation, numerical methods and experimental measurements for two wave heights.

A comparative study using various established partially non-linear methods and the model tests of S-175 was undertaken by ISSC (2000). The codes were fundamentally modifications of linear strip theory to account for the non-linear effects in various ways. The results from their study are reproduced in Figure 11, together with the predictions using the present method. Majority of the methods over-predict the amidships bending moment in the region of $\lambda / \mathrm{L} 0.7 \sim 1.2$. The idea behind comparing the validation studies conducted by ISSC with the coupled method is to get an outlook of the qualitative aspects of present method when compared with more established codes used in the industry and by researchers. Apart from the inevitable uncertainties in measurements, it can be stated with confidence that the co-simulations is capable of predicting the linear wave loads to a similar degree of accuracy, if not better. Nevertheless, the drawback of the CFD/FEA method is the computational time required to carry out these predictions which makes the 2-D linear methods more efficient for the first harmonic wave loads. Another salient feature from the plots is that the 2-D linear prediction is able to give a good estimation of the first harmonic bending moment when compared to other methods of varying complexity. It is, therefore, a very useful tool to evaluate the bending moments amidships and decide the scantlings in the initial design phase of the vessel. 


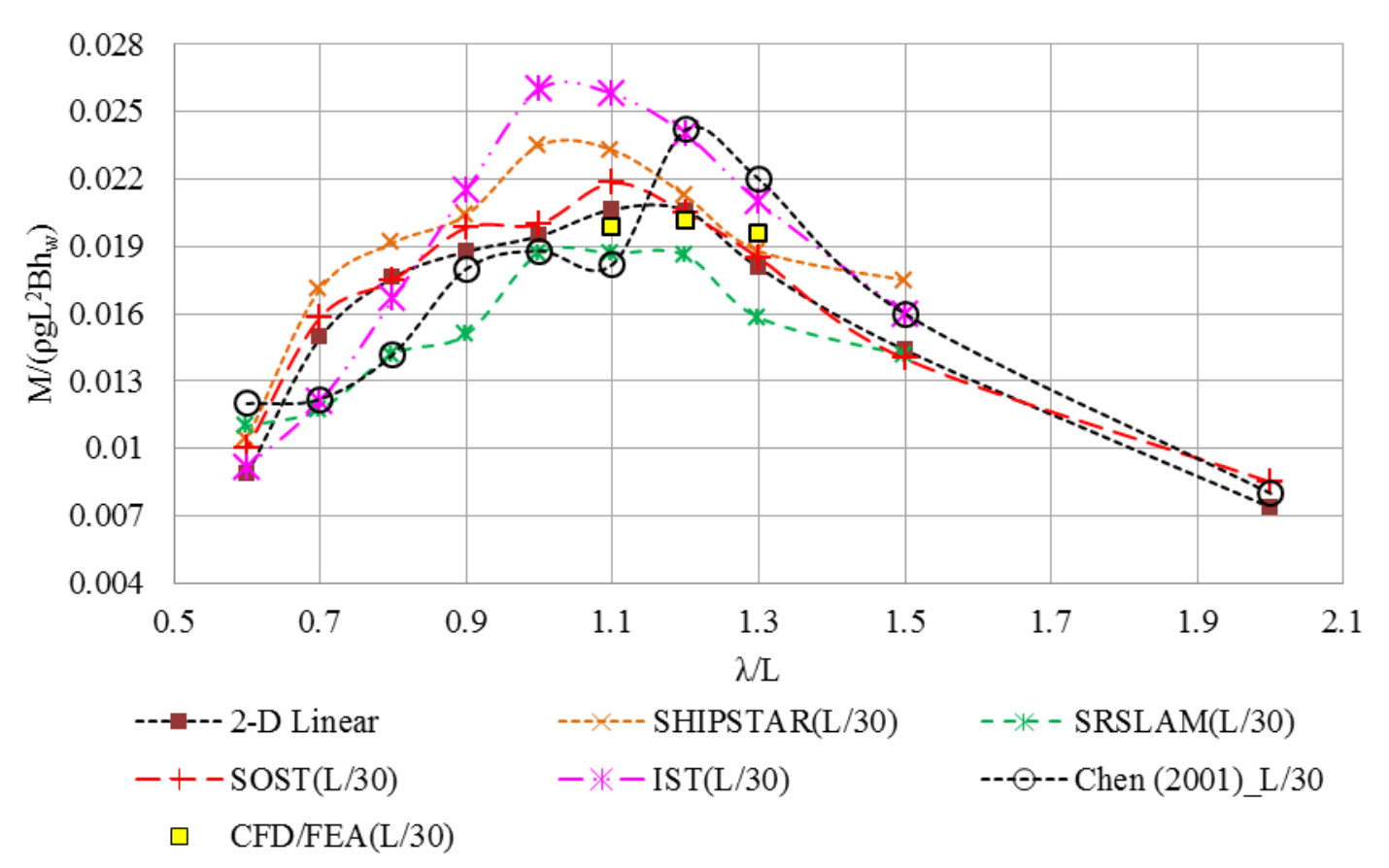

Figure 11: Non-dimensional amplitudes of first harmonic VBM amidships calculated by the linear coupled and co-simulation methods and the weakly nonlinear methods by ISSC. (2000). Measurements from Chen et al. (2001) are also shown.

The bending moments for $\mathrm{H} / \mathrm{L}=50$ at Point 1 and 5 (aft and forward, respectively), shown in Figure 12, display larger dissimilarities when compared with the experiments. Comparing the aft and forward locations, the co-simulation predictions are in better agreement with the experiments at point 1, aft of amidships. At point 5, 2-D linear greatly under-predicts the bending moments at all wave frequencies by a maximum of about $80 \%$ around the ship-wave matching region. Here the co-simulations are slightly better. It is worth noting that generally the co-simulation predicts the first harmonic bending moments accurately at all locations in the shorter wavelength $\lambda / \mathrm{L}=0.6 \sim 0.9$.

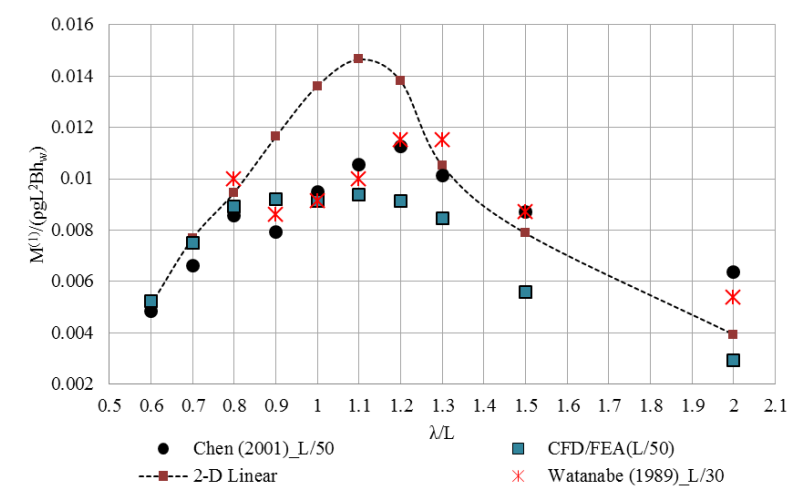

(a)

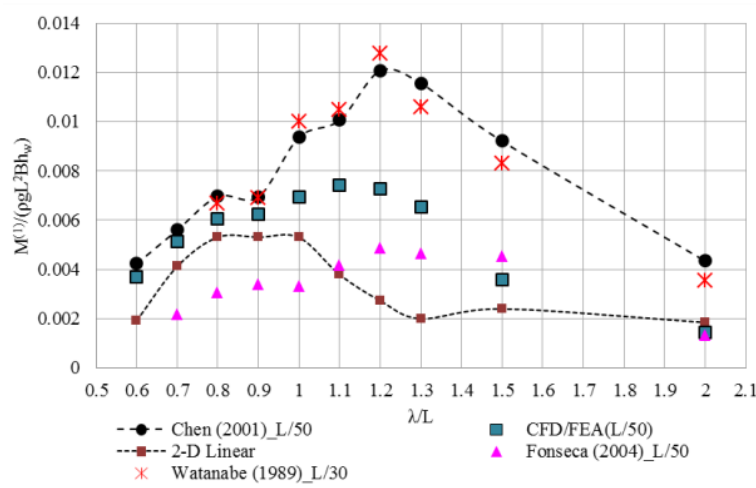

(b) 
Figure 12: Non-dimensional amplitude of first harmonic VBM at (a) Pt.1 (0.95 m from aft Lpp) and (b) Pt.5 (2.65 $\mathrm{m}$ from aft Lpp) calculated using co-simulation, numerical methods and experimental measurements for two wave heights.

\subsection{Nonlinear effects in wave load of S-175 in head waves}

The second harmonic of bending moment amidships calculated using CFD/FEA and measured from experiments are shown in Figure 13. The numerical predictions at amidships have maximum values that vary between $15 \%$ and $30 \%$ of the first-harmonic amplitudes, whereas in the experiments by Chen et al. (2001) it varies between $2 \%-10 \%$ of the first harmonic. The numerical predictions estimate higher second harmonics $(\lambda / L=1 \sim 1.5)$ compared to Chen et al. (2001), but produce good agreement with the measurements by Watanabe et al. (1989), the latter for slightly higher speed. In steep waves, the aforementioned two experiments record large differences, considering the fact that a flexible self-propelled model is used in both. With increase in wave height the predicted second harmonics get stronger in the numerical predictions to about $11-30 \%$ of the first harmonic in the range of $\lambda / \mathrm{L}=1.1 \sim 1.3$.

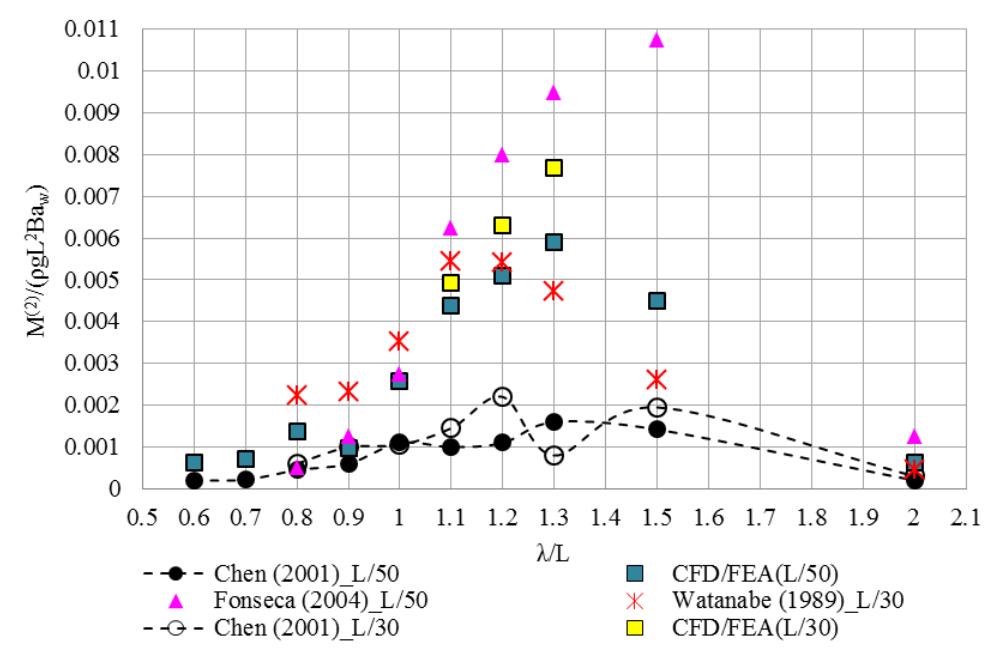

Figure 13: Non-dimensional amplitudes of second harmonic component of VBM amidships.

The influence of nonlinearities induced due to green water effects and bow immersion reflects in the second harmonics of bending moment towards the bow and stern of the vessel, shown in Figure 14. Point 5 and Point 1 are at $1 / 4 \mathrm{~L}$ from the F.P and A.P of the model, respectively. The maximum values at this location attain about 50-60\% of the first harmonics in the region of $\lambda / L=1.0 \sim 1.5$. The comparison between Fonseca \& Guedes Soares (2004b) as well as Watanabe et al. (1989) and the present method is quite good at the forward location, however at the aft location the responses measured by (Watanabe 
et al., 1989) is nearly twice as large as the numerical predictions in the range of $\lambda / \mathrm{L}=0.8 \sim 1.2$.

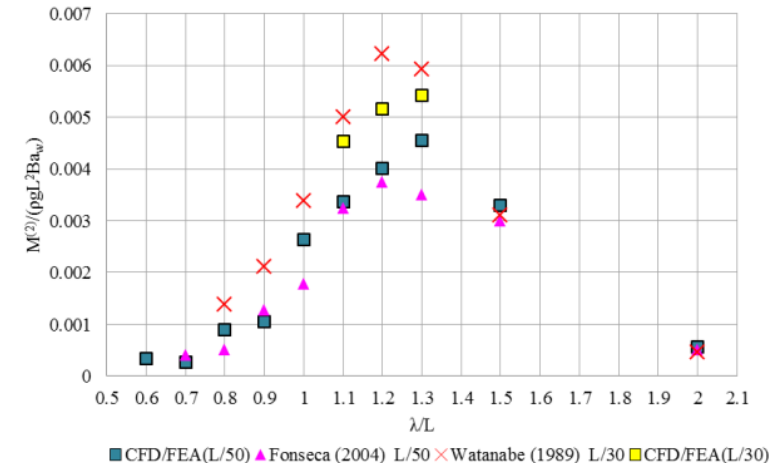

(a)

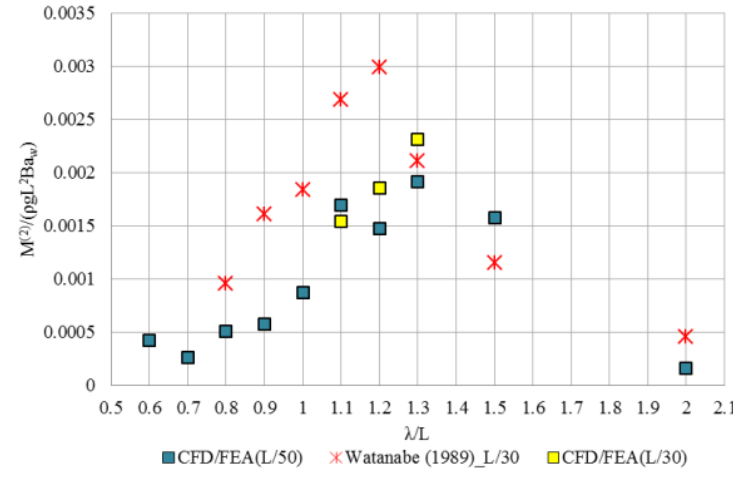

(b)

Figure 14: Non-dimensional amplitudes of second harmonic component of VBM at (a) Point 5 and (b) Point 1 It is obvious from the plots (Figure 13 and Figure 14) that the uncertainties in measurements can be larger in the case of the nonlinear components than the first harmonics.

The third harmonics of vertical bending moment at amidships and the fore quarter are shown in Figure 15. Once again the CFD/FEA tends to overestimate the nonlinear effects when compared to Chen et al. (2001), by about twice, in the region of $\lambda \mathrm{L}=1.1 \sim 1.3$. Nevertheless, the comparison is better than the second harmonic predictions. In general, a good agreement is achieved in the case of the third harmonics. The numerical predictions reveal that at amidships the third harmonics are of the order of $5-10 \%$ of the first harmonics. It is noteworthy that the co-simulation is able to capture even the relatively weaker nonlinear effects in the wave loads to acceptable level of accuracy. This would mean that, in cases where the nonlinear effects could be stronger, the method presented could be used to make estimations with good engineering accuracy.
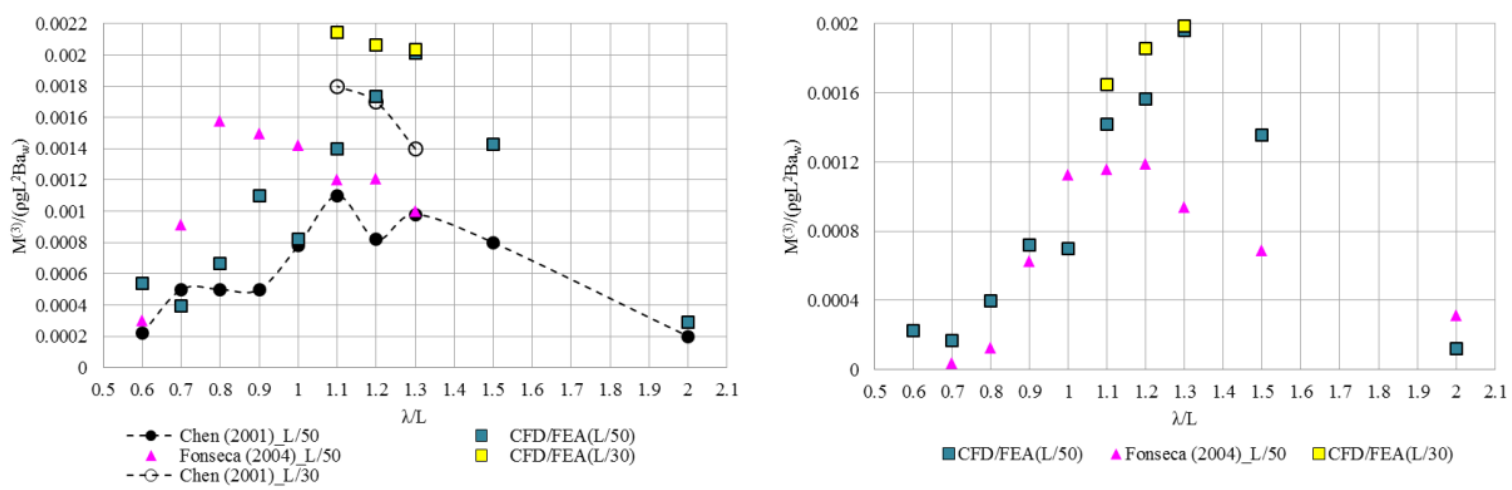
Figure 15: Non-dimensional amplitudes of the third harmonic component of VBM at (a) amidships (b)

Point5.

The 2-node flexible mode component of the vertical bending moment amidships is shown in Figure 16. The numerical predictions agree well at some wave frequencies, although there is substantial deviation at certain frequencies. The order of magnitude of the 2-node component is similar to the experiments, except at $\lambda / \mathrm{L}=1.0$ and 1.2. The predictions show an anomaly at $\lambda / \mathrm{L}=1.0$ and 1.2 and the predicted response is larger by nearly 6 times that of the measurements. The presence of higher frequency components was clearly identifiable in the time histories of bending moments. The predictions for $\mathrm{H}=\mathrm{L} / 30$ is good when compared to experimental measurements for the three wavelengths investigated. The time history of non-dimensionalised vertical bending moment for a few wave cycles in the region of $\lambda / \mathrm{L}=1.0 \sim 1.3$ is shown in Figure 17. The presence of higher frequency components is clearly noticeable in the time traces and the magnitude is considerably higher for $\mathrm{\lambda} / \mathrm{L}=1.0$ and 1.2 when compared to the other wavelengths shown in the figure.

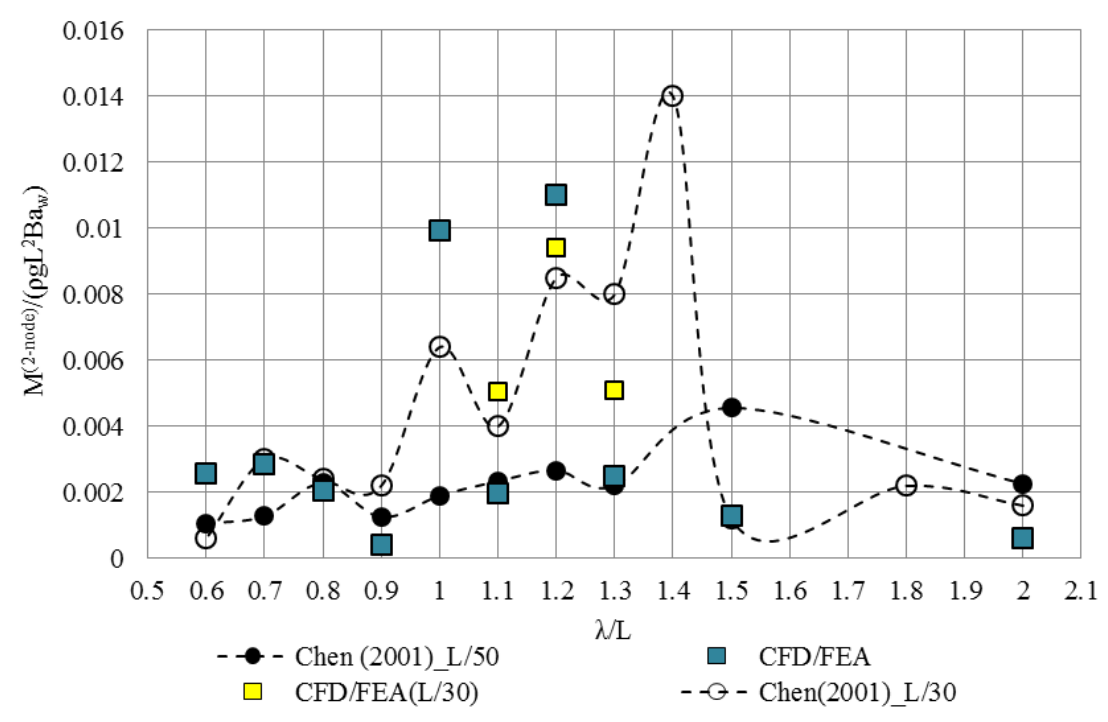

Figure 16: Non-dimensional amplitudes of the 2-node component in VBM amidships. 


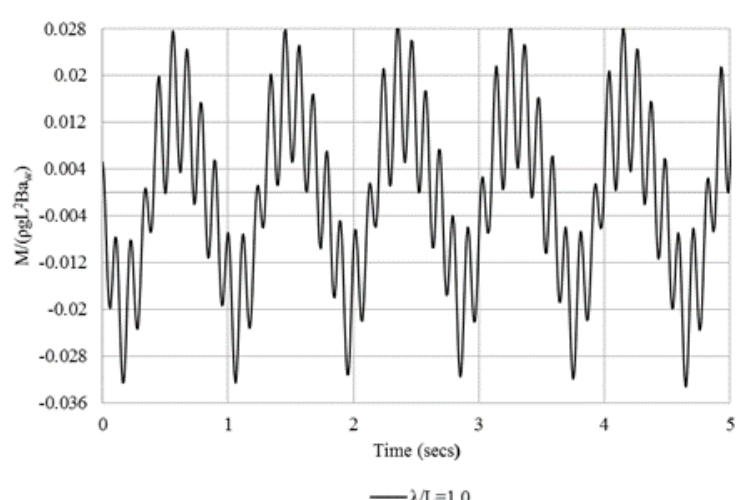

(a)

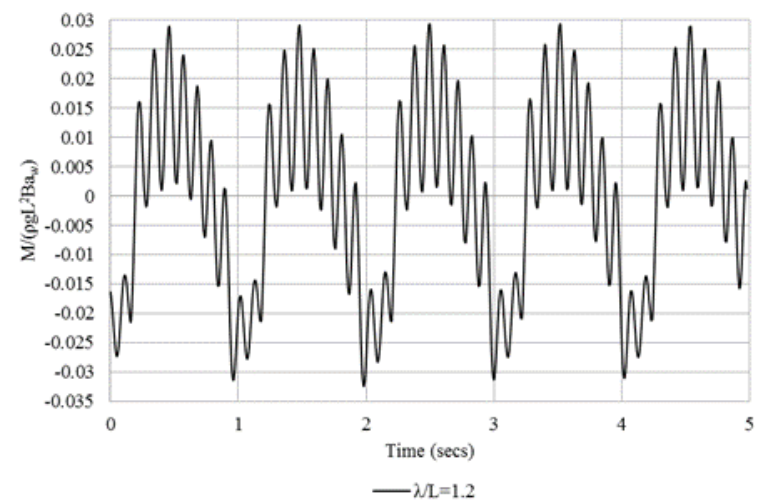

(c)

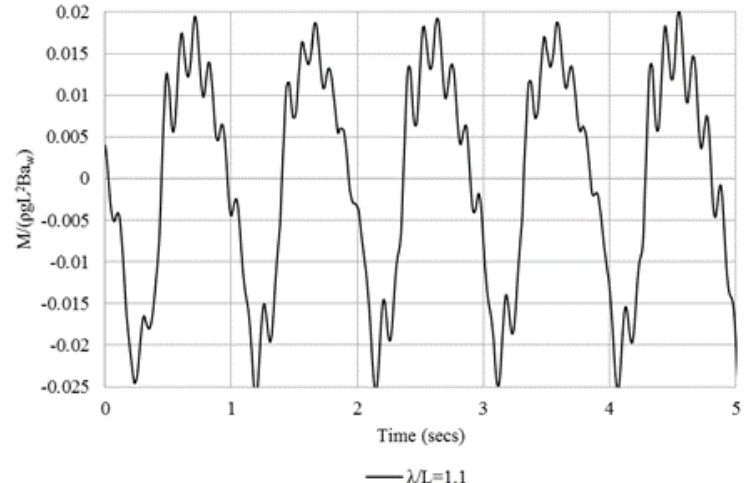

(b)

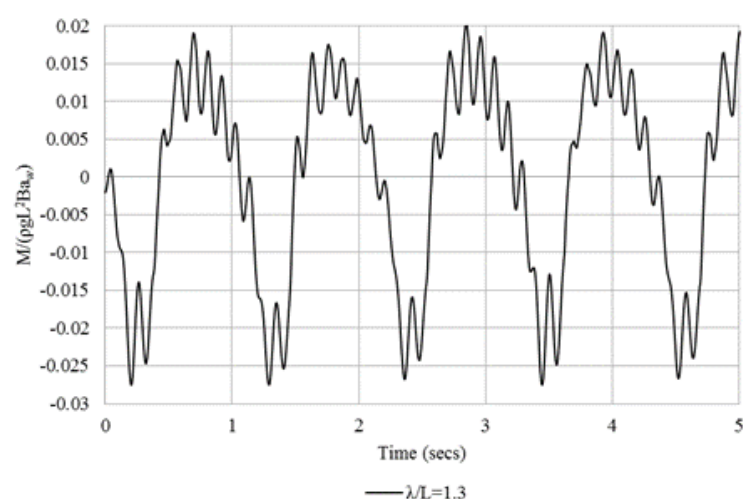

(d)

Figure 17: Time histories of total VBM amidships from coupled simulations for four wave frequencies $(\mathrm{H} / \mathrm{L}=1 / 50)(\mathrm{a})$ $\lambda / \mathrm{L}=1.0$ (b) $\lambda / \mathrm{L}=1.1$ (c) $\lambda / \mathrm{L}=1.2$ (d) $\lambda / \mathrm{L}=1.3$

Nonlinear springing component has been observed in hydroelastic model tests when the encounter frequency can be expressed as:

$f_{e}=f / N$,

where $f_{e}$ is the wave encounter frequency, $f$ is the 2-node structural wet frequency and $\mathrm{N}$ is an integer from 2 to $\mathrm{n}$. The order $\mathrm{N}$ indicates the nonlinear order of springing i.e., second-order, third-order and so on. A similar phenomenon seems to be occurring for this containership in waves, and the reason for large high frequency component at two discrete frequencies becomes obvious by observing the FFT signal of the bending moments amidships (Figure 18 and Table12). The smaller wave height is used to explain the observations due to the same number of test cases simulated as the experiments. Please note that the discussions are pertaining to the present numerical model with no structural damping. The findings might prove to be important when carrying out predictions for 
large containerships whose 2-node frequency may be lower than the present ship. Table 12 shows the wave encounter frequency and the frequency at which the 2-node responses appear in the FFT signal. This information is used to discuss certain chief aspects of the high frequency response.

1. At $\lambda / \mathrm{L}=1.2$ and 1.0 the harmonic order $\mathrm{N}$ is a perfect integer corresponding to the ninth and eighth order harmonic component, respectively. Even though the wet frequency is not estimated for the numerical model, Table 12 reveals that it is $8.88 \mathrm{~Hz}$ which appears at several wave conditions. When the encounter wave frequency is a higher-order of the wet natural frequency $(f / N)$, nonlinear resonant/springing condition occurs resulting in large amplitude of high frequency response (Miyake et al., 2009). Assuming no structural damping in numerical model, the magnitude of the high frequency response is about $40 \%$, see Figure 188, of the first harmonic of the bending moment; alarming for a relatively rigid ship as S-175.

2. In shorter waves $(0.6 \sim 0.8)$, the high frequency component coincides with the wet natural frequency $(8.88 \mathrm{~Hz})$ producing considerable magnitudes. Even though, the order $\mathrm{N}$ is not a perfect higher-order of the wet natural frequency the response creates a resonant condition leading to relatively strong responses.

3. By contrast to that, at $\lambda / \mathrm{L}=1.1$ and 1.3 , the 2-node responses are of the same magnitude as the shorter wavelengths but this should not be confused as a resonant behaviour. Although, it is termed as 2-node following the same conventions as Chen et al. (2001), it is distinctly a higher harmonic effect, namely the ninth and tenth harmonic, respectively (see Table 12). The term 'higher order harmonic effect' means that it is a higher order of the wave encounter frequency which is not coinciding with the 2 -node wet frequency of the model $(8.88 \mathrm{~Hz})$. The nonlinear behaviour in this case is caused by the nonlinearities due to the green water and flare impact only.

4. The tenth-order of the wet natural frequency $(8.88 \mathrm{~Hz})$ is equal to $0.88 \mathrm{~Hz}$ and the corresponding $\lambda / \mathrm{L}$ is equal to 1.4. According to the explanation in point 1 , the model should be experiencing a nonlinear resonant behaviour at this wave frequency.

5. To investigate the occurrence of nonlinear higher order springing at a couple of other wave frequencies, two simulations were performed corresponding to the seventh and tenth order of the 2 -node wet frequency of the model $(\lambda / \mathrm{L}=1.4 \& 0.833)$. In Table 12 , these two frequencies are distinguished using bold blue colour. It must be noted that at 
$\lambda \mathrm{L}=0.833$, corresponding to the seventh harmonic order, no green water on deck was observed in the CFD simulations. The FFT of VBM amidships is shown in Figure 18 along with the $\lambda / \mathrm{L}=1.2 \& 1.0$. The magnitude of 2 -node response for these two frequencies is nearly 2.5-3.0 times higher than responses at other wave frequencies in Table 12. The nonlinear resonant behaviour is also noted at these frequencies as well. The water shipped on the deck also has a dominant effect on the nonlinear higher order harmonic springing, and hence, the responses at these two additional frequencies are smaller than $\lambda / \mathrm{L}=1.2 \& 1.0$. This is an interesting phenomenon which is revisited in the next section where the influence of structural damping is examined.

From the above, we understand that when a flexible model with forward speed encounters regular waves, the 'higher-order springing' and the 'higher-order harmonics' of the wave encounter frequency can become extremely important. Moreover, these are two separate nonlinear behaviour characteristics, and must be carefully considered when planning experiments or even in numerical calculations. Please note that these higher-order responses are induced due to the green water impulse on the deck. It is a combination of whipping and nonlinear springing that is observed for $\lambda / \mathrm{L}=1.0,1.2$ and 1.4. It is paramount that while conducting measurements or numerical calculations one should include the discrete frequencies where the occurrence of a nonlinear resonant behaviour is suspected.

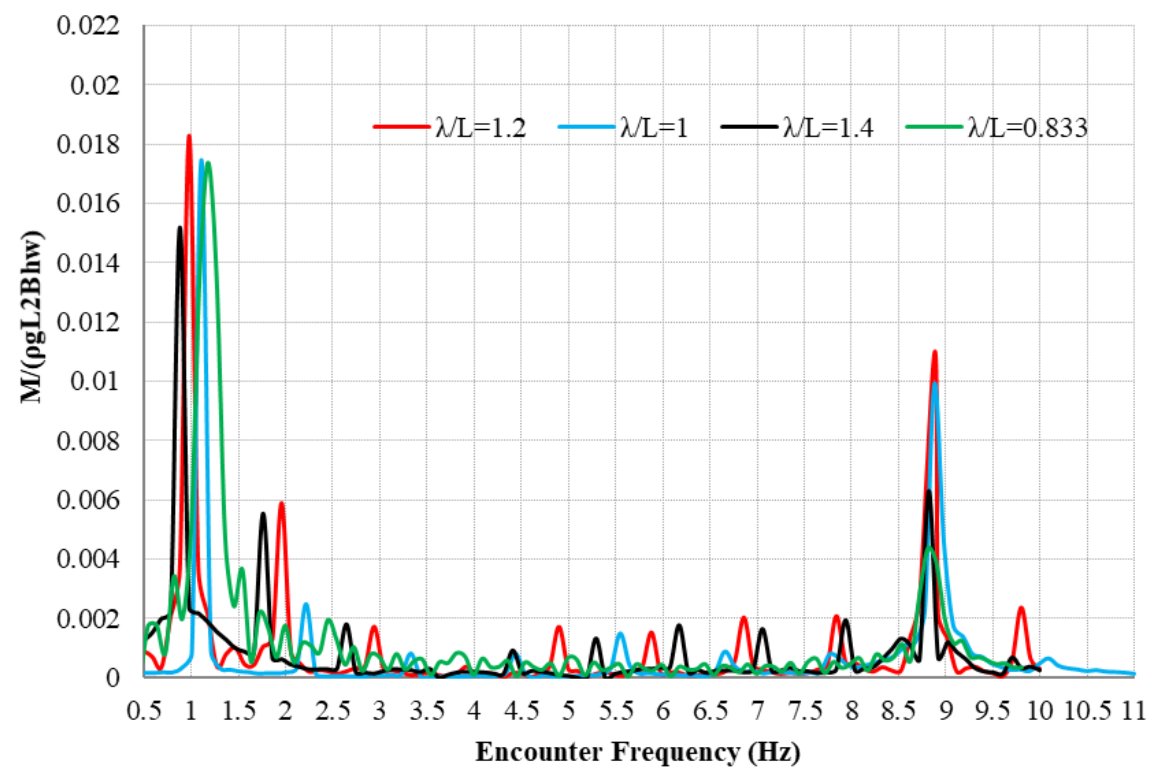

Figure 18: Frequency response of the VBM amidships at conditions exhibiting nonlinear higher order for various $\lambda / \mathrm{L}$ ratios. 
Table 12: Relationship between the wave encounter frequency and the 2-node component calculated in the VBM amidships using FFT and their respective higher-order

\begin{tabular}{|c|c|c|c|}
\hline & Encounter frequency $(\mathrm{Hz})$ & 2-Node component $(\mathrm{Hz})$ & Harmonic Order ' $N$ ' \\
\hline 0.6 & 1.6067 & 8.88 & 5.5 \\
\hline 0.7 & 1.4356 & 8.88 & 6.2 \\
\hline 0.8 & 1.3037 & 8.88 & 6.8 \\
\hline 0.833 & 1.266 & 8.88 & 7.0 \\
\hline 0.9 & 1.1985 & 8.42 & 7.0 \\
\hline 1.0 & 1.1125 & 8.88 & 8.0 \\
\hline 1.1 & 1.0405 & 9.33 & 8.9 \\
\hline 1.2 & 0.9794 & 8.88 & 9.0 \\
\hline 1.3 & 0.9267 & 9.25 & 10.0 \\
\hline 1.4 & 0.888 & 8.88 & 10.0 \\
\hline 1.5 & 0.8403 & 9.25 & 11 \\
\hline 2.0 & 0.6926 & 8.91 & 12.8 \\
\hline
\end{tabular}

\subsection{Effect of structural damping on the wave loads}

Wu et al. (2003) estimated the 2-node damping ratio of S-175 model in still water from the time history of amidships impulse-exciting responses amidships to be 0.067 . This damping ratio is a combination of hydrodynamic and structural damping. In this case, the structural damping is estimated approximately as $1 \%$ of critical damping. This value is calculated from the case studies of ships in Bishop \& Price (1979) which gives an approximate structural damping vs hydrodynamic damping comparison. Rayleigh's damping is used to assign structural damping, corresponding to $1 \%$ critical damping, to the beam model using only the mass proportional damping ratio $\alpha$. The value of structural damping ratio given as an input is 0.0101 .

The wave loads are recalculated using structural damping for $\lambda / L=1.0 \sim 1$. 3. The numerical predictions of the first and higher harmonic contributions and the 2 - node component are 
shown in Figure 19. The first harmonic of the bending moment shows marginal variation that is as expected. Regarding the higher order harmonics, the numerical predictions, by and large, either move closer towards the experiments by Chen et al. (2001) or exhibit negligible change.

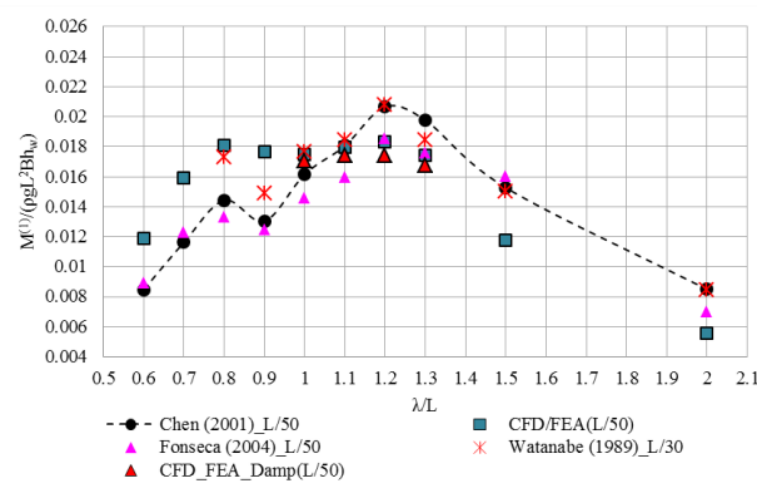

(a)

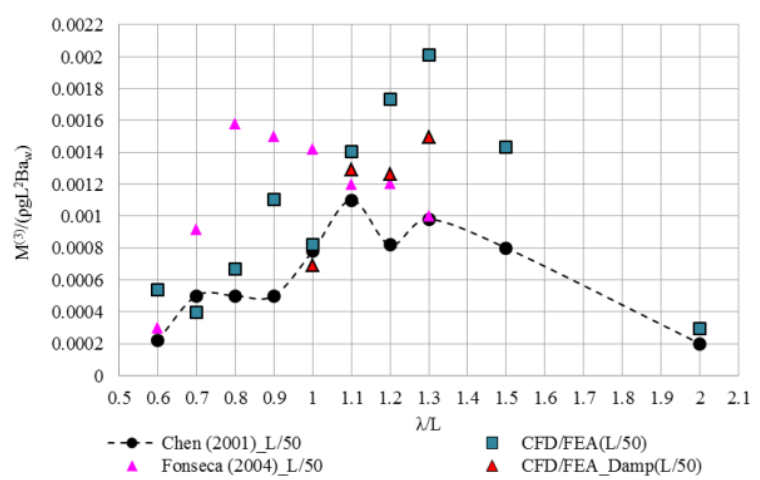

(c)

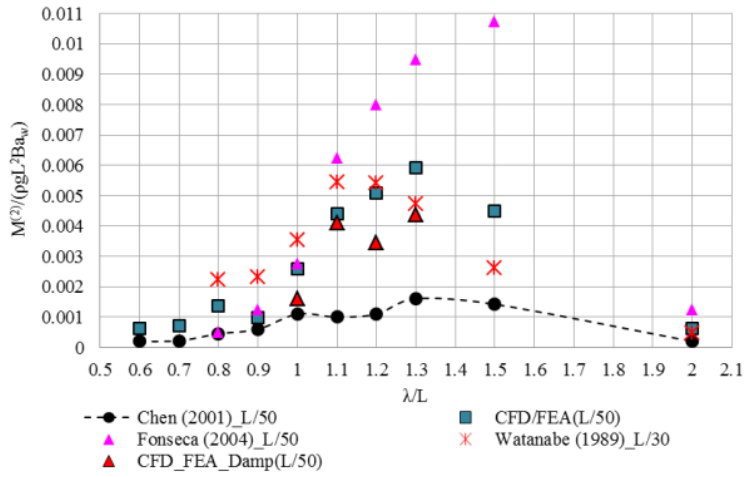

(b)

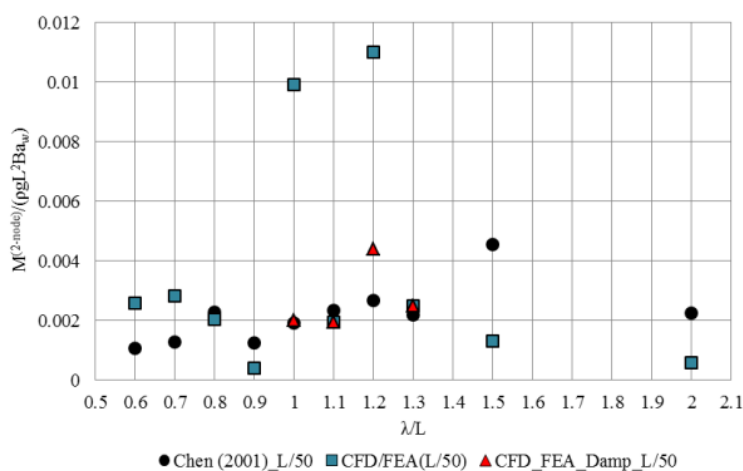

(d)

Figure 19: Non-dimensional amplitudes of (a) first harmonic of VBM (b) second harmonic (c) third harmonic (d) 2-node component amidships with and without Rayleigh's structural damping in the FE model of S-175.

There is a marked improvement in the simulations with respect to the 2-node flexible component for $\lambda / L=1.0$ and 1.2 and decreases by about $60-70 \%$ when compared to the undamped case. Among the four simulations performed with the inclusion of damping, the model experiences nonlinear springing (resonant phenomena) of the eighth and ninth order for the aforementioned wave frequencies. The simulations indicate that the structural damping affect only the high-frequency resonant vibrations and not the higher order harmonic responses of the wave encounter frequencies. The S-175 model studied in this paper is relatively rigid when compared to modern containerships or large flexible floating structures. For a modern flexible containership, these nonlinear resonant effects could become extremely important since their contribution to the wave-induced loads 
could be significant. The high frequency damping in the time history of bending moment for $\lambda / L=1.2$ can be seen in Figure 20. For the damped case, there is a massive change in the magnitude of the 2-node component.

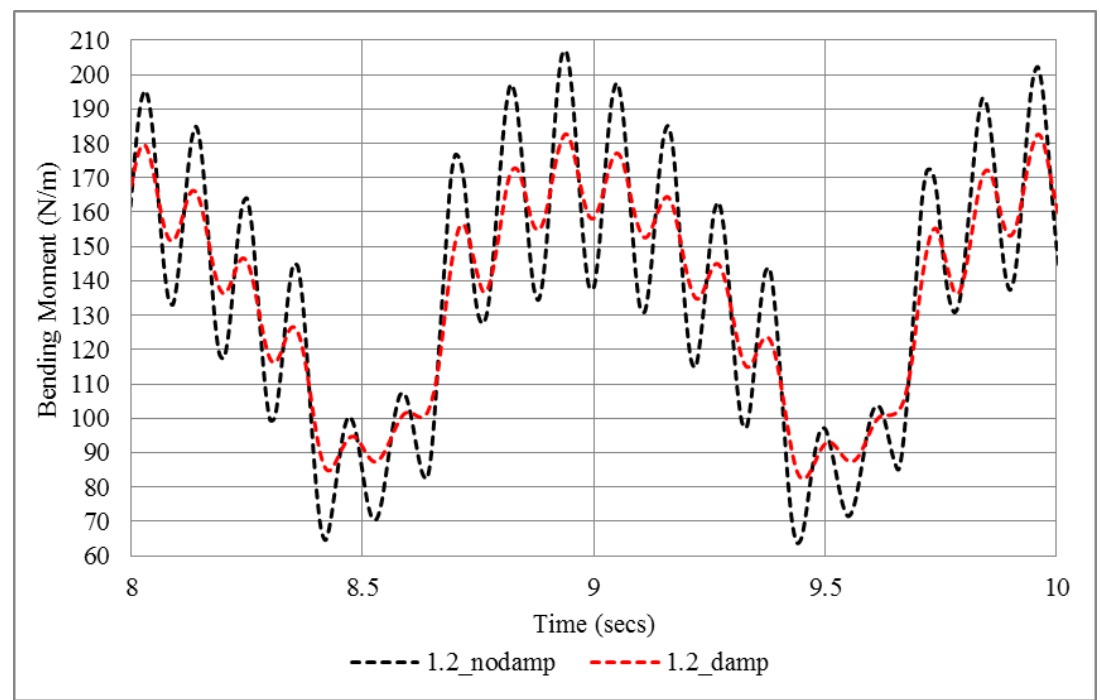

Figure 20: Time history of VBM amidships with and without damping in the FE model for $\lambda / \mathrm{L}=1.2$

\subsection{Asymmetry in Hogging and Sagging wave loads}

The non-dimensionalised hogging (assumed +ve) and sagging loads measured showed appreciable asymmetry and the nonlinearity increases with increase in wave height, see Figure 2121. In the region of $\lambda / \mathrm{L}=1.0 \sim 1.3$ the measurements the maximum divergence of the non-dimensionalised sagging moments is 0.01 , with the peak sagging occurring at $N / L=1.2$. The numerical prediction with and without damping are shown in Figure 2121 . There is a reasonable agreement in the hog/sag loads with minor differences in the short wave lengths. Once again it is seen that the inclusion of damping improves the predictions, especially for the wavelengths $\mathrm{N} / \mathrm{L}=1.0$ and 1.2. Around the ship-wave matching region, the hog/sag asymmetry is evident in the numerical predictions. For the steeper wave, the sagging loads are about $40-55 \%$ higher than the hogging wave loads. The asymmetry in wave loads is well captured by the co-simulation and there is a good agreement with experiments. Linear potential flow methods are incapable of calculating the asymmetry in the wave loads and predict equal magnitudes for the hogging and sagging. 


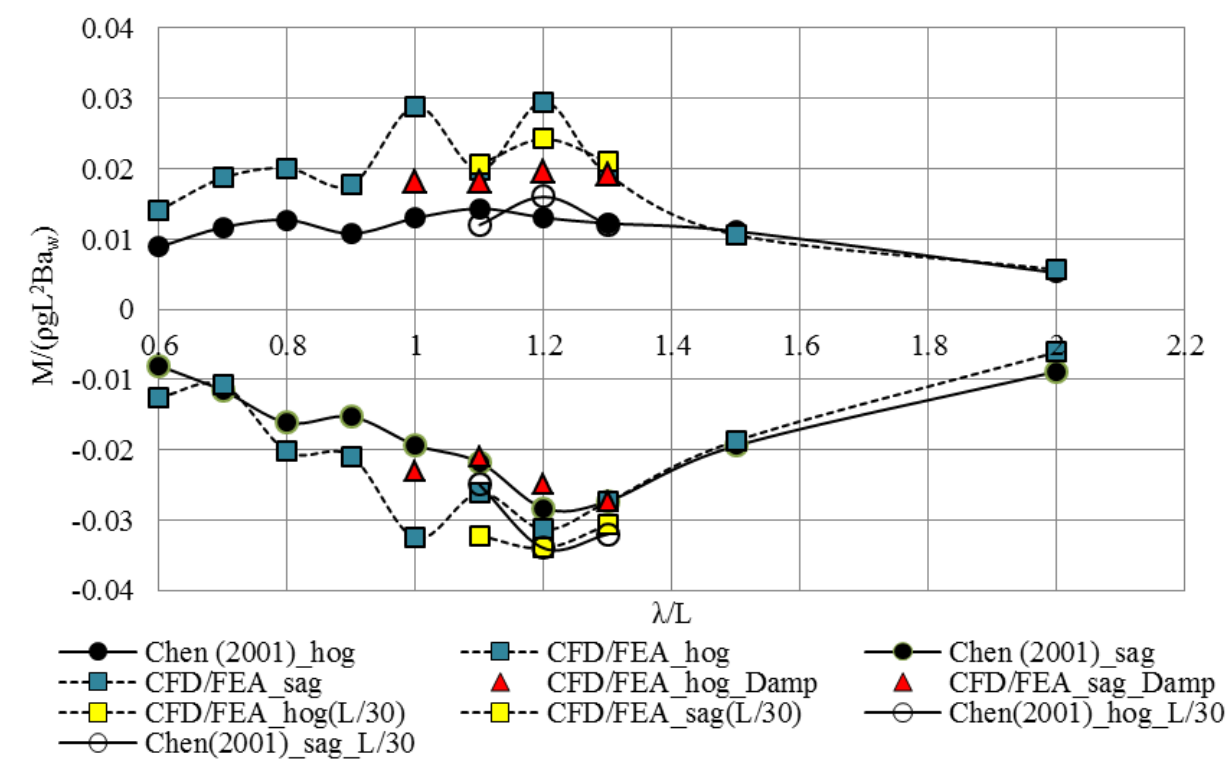

Figure 21: Non-dimensional amplitudes of hogging and sagging VBM amidships with and without Rayleigh's structural damping is vs measurements from (Chen et al., 2001)

\section{Concluding Remarks}

A flexible S-175 containership model with forward speed is used to validate the CFD/FEA co-simulation predictions by comparing the motions and wave loads in regular head waves with experimental measurements of Chen et al. (2001) and others and 2-D linear hydroelastic code.

The vertical motions predicted by the present method generally agreed well with the measurements except at a few wave lengths $(\lambda / \mathrm{L}=1.1 \sim 1.5)$. In this region, they were over predicted by a maximum of about $30 \%$ for the smaller wave height. The 2 -D linear hydroelastic code also over predicted the motion in this region by a maximum of about $40 \%$. The vertical accelerations at the bow for the two wave heights showed excellent agreement with the measurements for all wave frequencies investigated.

The agreement of the first harmonic of bending moment amidships predicted around the resonant region (ship-wave matching region) agreed well with measurements. In longer waves, the first harmonic amidships was under predicted by about $30-35 \%$ when compared with measurements and 2-D linear hydroelasticity. It can be concluded that the CFD/FEA co-simulation for the S-175 containership predicts the first harmonic bending moments amidships to a similar degree of accuracy of the linear and nonlinear strip theories. 
The second and third harmonics of VBM compared with three experimental measurements revealed that the predictions are capable of capturing the nonlinearities in wave loads at amidships and fore and aft of the model to a good degree of accuracy. The present method predicts stronger second harmonic component when compared with Chen et al. (2001) but agrees well with Watanabe et al. (1989). The nonlinear loads measured by the experiments showed more scatter than the linear wave loads. The 2 -node flexible mode of the vertical bending moment amidships for two wave heights calculated using the co-simulation showed excellent agreement with the experimental measurements except at two frequencies for $\mathrm{H} / \mathrm{L}=1 / 50$.

The relatively high frequency component in the wave load is due to occurrence of two different nonlinear phenomena, namely higher-order springing and higher-order harmonic of wave encounter frequency, which is stated together as 2-node flexible mode in the experiments as they both occur in the vicinity of the 2-node wet frequency. In general, the contribution of nonlinear or higher-order springing to the wave load is stronger than the higher-order harmonic contribution. It is important to identify these conditions and evaluate when carrying out a detailed hydroelastic investigation of a vessel.

Thus, it is concluded that the co-simulation demonstrated the capability of capturing all aspects of nonlinear behaviour to a good degree of accuracy. It has also aided in revealing the effect of higher-order behaviour, greater than second-order or third order which would otherwise not be possible with weakly nonlinear potential flow codes, including the influence of structural damping.

Our conclusions were drawn for a relatively rigid ship and mostly without accounting for structural damping. It is our belief that the aspects of nonlinear behaviour we refer to will be very important for modern flexible containerships, where the magnitude of these nonlinear effects could be large and CFD/FEA co-simulation could be a useful tool to in identifying them.

A single mesh (for each wave height) is used in the co-simulations for a range of wave frequencies investigated. This methodology might be neglecting certain key fundamentals of CFD investigations, with only limited studies on grid convergence, but has proved to be numerically efficient. The effect of grid refinement on the linear and nonlinear wave load predictions is to be carried out systematically to draw insights that are more detailed on the differences. 
Future work should focus on (i) comparisons between one-way and two-way coupling to predict the linear and nonlinear wave loads, (ii) performing co-simulation in oblique seas which includes coupled antisymmetric horizontal-bending and twisting (iii) performing co-simulation in long- and short-crested irregular waves with focus on whipping, springing and their influence on fatigue life (iv) carry out more extensive spatial convergence studies to obtain insights into the uncertainties involved in the fluid model.

\section{Acknowledgements}

The authors acknowledge the support of the Lloyd's Register Foundation through its University of Southampton Technology Centre in Ship Design for Enhanced Environmental Performance and the Engineering and Physical Sciences Research Council (EPSRC).

\section{References}

Andersen, I.M. V, 2014. Full scale measurements of the hydro-elastic response of large container ships for decision support. Technical University of Denmark.

Baso, S., Matsuda, H., Kurihara, T., Kurokawa, T., Doi, Y., Sji, J., 2010. An Eulerian scheme with lagrangian particles for evaluation of seakeeping performance of a ship in nonlinear wave, in: ISOPE.

Benhamou, A., Seng, S., Monroy, C., de Lauzon, J., Malenica, S., 2018. Hydroelastic simulations in OpenFOAM: A Case Study on a 44000 TEU Containership, in: 8th International Conference on Hydroelasticity in Marine Technology. pp. 351-362.

Benra, F.K., Dohmen, H.J., Pei, J., Schister, S., Wan, B., 2011. A comparison of one-way and two-way coupling methods for numerical analysis of fluid-structure interactions. Journal of Applied Mathematics 16 pages.

Bishop, R.E.D., Chalmers, D.W., Price, W.G., Temarel, P., 1986a. The dynamic characteristic of unsymmetrical ship structures. Trans. R. Inst Nav. Architects 128, $205-215$.

Bishop, R.E.D., Price, W.G., 1979. Hydroelasticiy of Ships. Cambridge University Press.

Bishop, R.E.D., Price, W.G., Tam, P.K.Y., 1977. A unified dynamic analysis of ship response to waves. Trans. R. Inst Nav. Architects 119, 363-390.

Bishop, R.E.D., Price, W.G., Temarel, P., 1980. A unified dynamic analysis of antisymmetric ship response to waves. Trans. R. Inst Nav. Architects 27, 54-65.

Bishop, R.E.D., Price, W.G., Wu.Y, 1986b. A general linear hydroelasticity theory of floating structures moving in a seaway. Phil. Trans. R. Soc. Lond A316, 375-426.

Brummelen, van E.H., 2011. Partitioned iterative solution methods for fluid-structure interaction. Internationa journal for numerical methods in fluids $65,3-27$. https://doi.org/10.1002/fld.2465 
Carrica, P.M., Wilson, R. V, Stern, F., 2006. Unsteady RANS simulation of the ship forward speed diffraction problem. Computers \& Fluids 35, 545-570.

https://doi.org/10.1016/j.compfluid.2005.08.001

Causin, P., Gerbeau, J.F., Nobile, F., 2005. Added-mass effect in the design of partitioned algorithms for fluid-structure problems. Computer methods in applied mechanics and engioneering 194, 4506-4527.

https://doi.org/10.1016/j.cma.2004.12.005

Chapchap, A., Ahmed, T.M., Hudson, D.A., Temarel, P., Hirdaris, S.E., 2011. The influence of forward speed and nonlinearities on the dynamic behaviour of a container ship in regular waves. Trans. R. Inst Nav. Architects Part A: InternationalJournal of MEritime Engineering 153, 137-148.

Chen, R.Z., Du, S.X., Wu, Y.S., Lin, J.R., Hu, J.J., Yue, Y.L., 2001. Experiment on extreme wave loads of a flexible ship model, in: PRADS. pp. 871-878.

Clough, R.W., Penzien, J., 1993. Dynamics of Structures. McGraw-Hill, Berkely, CA.

Dassault Systèmes, 2013. Abaqus 6.13-1 Manual. Providence, RI, USA.

Du, S.X., Wu, Y.S., Price, W.G., 1998. Forward speed effect on structural responses of a ship travelling in waves, in: In Proceedings of the 2nd International Conference on Hydroelasticity in MArine Technology. Fukuoka, Japan, pp. 401-410.

El Moctar, O., Ley, J., Oberhagemann, J., Schellin, T., 2017. Nonlinear computational methods for hydroealstic effects of ships in extreme seas. Ocean Engineering 130, 659-673.

Ferziger, J.., Peric, M., 2003. Computational Methods for Fluid Dynamics, 3rd Editio. ed. Springer, Berlin.

Fonseca, N., Guedes Soares, C., 2004a. Experimental Investigation of the Nonlinear Effects on the Vertical Motions and Loads of a Containership in Regular Waves. J. Ship Res. 48, 118-147.

Fonseca, N., Guedes Soares, C., 2004b. Experimental Investigation of the Nonlinear Effects on the Statistics of Vertical Motions and Loads of a Containership in Irregular Waves. J. Ship Res. 48, 148-167.

Fonseca, N., Soares, C.G., 2005. Comparison between experimental and numerical results of the nonlinear vertical ship motions and loads on a containership in regualr waves. International Shipbuilding Progress 52, 57-89.

Gao, R., Ren, B., Wang, Y., 2012. Numerical modelling of regular wave slamming on subface of open-piled structures with the corrected SPH method. Appl. Ocean Res. 34, 173-186.

Hirdaris, S.E., Temarel, P., 2009. Hydroelasticity of ships: Recent advances and future trends. In Proceedings of the Institution of Mechanical Engineers, Part M: J. Engng Maritime Environment 223, 305-330. https://doi.org/10.1243/14750902JEME160

Hirt, C.W., Nichols, B.D., 1981. Volume of Fluid (VOF) method for the dynamics of free boundaries. Journal of Computational Physics 39, 201-225.

Iijima, K., Yao, T., Moan, T., 2008. Strutural response of a ship in severe seas 
considering global hydroelastic vibrations. Marine Structures 21, 420-445.

ISSC., 2012. Report of Committee I.2: Loads. In Proceedings of the 18th International Ship and Offshore Structures Congress, Rostock, Germany 1, 79-150.

ISSC., 2000. Committee VI.1. Extreme Hull Girder Loading. Proceedings of the 14th International Ship and Offshore Structures Congress 2000, Vol. 2 (Eds. Ohtsubo, H. and Sumi, Y.).

ITTC., 2011. The Seakeeping Committe final report and recommendations. In the Proceedings of 26th ITTC, Rio de Janerio, Brazil 183-245.

ITTC, 2017. The Seakeeping Committe final report and recommendations. In the Proceedings of 26th ITTC, Copenhagen.

ITTC, 2011. Practical Guidelines for Ship CFD Applications, in: International Towing Tank Conference. pp. 1-18.

Jiao, J.L., Chen, Z.Y., Chen, C.H., 2019a. Time-domain hydroelastic analysis of nonlinear motions and loads on a large bow flare ship in high irregular seas. Journal of Marine Science and Technology 1-29.

Jiao, J.L., Yu, H.C., H, C.C., 2019b. Time-domain numerical and segmented model experimental study on ship hydroelastic responses and whipping loads in hard irregular seaways. Ocean Engineering 185, 59-81.

Kim, K.H., Kim, Y., 2014. Numerical analysis of springing and whipping using fullycoupled FSI models. Ocean Engineering 91, 28-50.

Kim, S.P., Lee, H., 2011. Fully nonlinear seakeeping analysis based on CFD simulations, in: In Proceedings of the 21st International Offshore and Polar Engineering Conference. Hawaii, U.S.A, pp. 970-974.

Lakshmynarayanana, P.A., Temarel, P., 2019. Application of CFD and FEA coupling to predict dynamic behaviour of a flexible barge in regular head waves. Marine Structures 65. https://doi.org/10.1016/j.marstruc.2019.02.006

Malenica, S., Moan, B., Remy, F., Senjanovic, I., 2003. Hydrelastic reponse of a barge to impulsive and non-impulsive wave loads, in: Hydroelasticity in Marine Technology. pp. 107-115.

Michler, C., Hulshoff, S.J., Brummelen, van E.H., de Borst, R., 2004. A monolithic approach to fluid-structure interaction. Computers \& Fluids 33, 839-848.

Miyake, R., Matsumoto, T., Zhu, T., Usami, A., Dobashi, H., 2009. Experimental studies on the hydroelastic response using a flexible Mega-Container ship model, in: Hydroelasticity in Marine Technology. pp. 161-171.

Muzaferija, S., Peric, M., Sames, P., Schellin, T., 1998. A Two-Fluid Navier-Stokes Solver to Simulate Water Entry, in: In Proceedings of the 22nd Symposium on Naval Hydrodynamics. Washinton, DC, pp. 277-289.

O’Dea, J., Powers, E., Zselecsky, J., 1992. Experimental determination of nonlieanrities in vertical plane ship motions, in: Proc. 19th Symposium on Naval Hydrodynamics. pp. $73-91$. 
Oberhagemann, J., Kromer, M., Cabos, C., El Moctar, O., 2012a. A fluid-structure coupling method based on field methods and a structural mode decomposition, in: Hydroelasticity in Marine Technology. pp. 267-276.

Oberhagemann, J., Shigunov, V., El Moctar, O., 2012b. Application of CFD in long-term extreme value analyses of wave loads. Ship Technology Research 59, 4-22. https://doi.org/10.1179/str.2012.59.3.001

Oberhagemann, J., Shigunov, V., Radon, M., Mumm, H., Won, S.-I., 2015. Hydrodynamic load analysis and ultimate strength check of an 18000 TEU containership, in: 7th International Conference on HYEL. pp. 591-605.

Paik, K.J., Carrica, P.M., Lee, D., Maki, 2009. Strongly coupled fluid-structure interaction method for structural loads on surface ships. Ocean Engng 36, 13461357.

Patankar, S. V, Spalding, D.B., 1972. A calculation procedure for hear, mass and momentum transfer in three-dimensional parabolic flows. Int. Journal of Heat and Mass Transfer 15, 1787-1806.

Peric, M., Zorn, T., El Moctar, O., Schellin, T., Kim, Y.S., 2007. Simulation of Sloshing in LNG-Tanks, in: OAME.

Piro, D.J., 2013. A Hydroelastic method for the analysis of global response due to slamming events. The University of Michigan.

Rugonyi, S., Bathe, K.J., 2001. On finite element analysis of fluid flows coupled with structural interaction. CMES-Comp. Modeling Eng. Sci. 2, 195-212.

Seng, S., 2012. Slamming and whipping analysis of ships. Denmark Technical University.

Seng, S., Andersen, I.M. V, Jensen, J.J., 2012. On the influence of hull girder flexibility on the wave, in: Proc. 6th Int.Conf. on Hydroelasticity in Marine Technology. Tokyo, Japan, pp. 341-353.

Sengupta, D., Pal, S.K., Datta, R., 2017. Hydroelasticity of a 3D floating body using a semi analytic approach in time domain. Journal of Fluids and Structures 71, 96115 .

Senjanovic, I., Malenica, S., Tomasevic, S., 2009. Hydroelasticity of large container ships. Marine Structures 22, 287-314.

STAR-CCM+, 2012. STAR-CCM+ version 8.04 manual [WWW Document].

Takami, T., Matsui, S., Oka, M., Iijima, K., 2018. A numerical simulations method for predicting global and local hydroelastic response of a ship based on CFD and FEA coupling. Marine Structures 59, 368-386.

Tallec, P. Le, Mouro, J., 2001. Fluid structure interaction with large dispalcements. Comput. Meth. Appl. Mech. Engrg 190, 3039-3067.

Tang, H.S., Jobes, S.C., Sotiropoulos, F., 2003. An overset-grid method for 3D unsteady incompressible flows. Journal of Computational Physics 191, 567-600.

Tezdogan, T., Demirel, Y.K., Khoransanchi, M., Incecik, A., Turan, O., 2015. Full scale 
unsteady RANS CFD simulations of ship behaviour and perforamnce in head seas due to slow steaming. Ocean Engineering 97, 186-206.

Tu, J., Inthavong, K., Wong, K.K.L., 2015. Computational Hemodynamics - Theory, Modelling and Applications. Springer Netherlands. https://doi.org/10.1007/978-94017-9594-4

Wang, Z.J., 1995. A fully conservative interface algorithm for overlapping grids. Journal of Computational Physics 122, 96-106.

Watanabe, I., Guedes Soares, C., 1999. Comparative study on the time-domain analysis of non-linear ship motions and loads. Mar.Structs 12, 153-170.

Watanabe, I., Keno, M., Sawada, H., 1989. Effects of bow flare shape on wave loads of a container ship. Journal of the Society of Naval Architects of Japan 166, 259-299.

Weymouth, G., Wilson, R., Stern, F., 2005. RANS Computational Fluid Dynamics Predictions of Pitch and Heave Ship Motions in Head Seas. Journal of Ship Research 49, 80-97.

Wu, M., Hermundstad, O.A., 2002. Time-domain simulation of wave-induced nonlinear motions and loads and its applications in ship design. Marine Structures 15, 561597. https://doi.org/http://dx.doi.org/10.1016/S0951-8339(02)00003-5

Wu, Y., Chen, R., Lin, J., 2003. Experimental Technique of Hydroelastic Ship Model, in: Hydroelasticity in Marine Technology. pp. 131-142.

Zhao, R., Faltinsen, O.M., 1993. Water entry of two-dimensional bodies. Journal of Fluid Mechanics 246, 593-612. 